\title{
Stable Water Isotope Simulation by Current Land- surface Schemes: Results of iPILPS Phase 1
}

\author{
A. Henderson-Sellers ${ }^{1}$, M. Fischer ${ }^{1}$, I. Aleinov ${ }^{2}$, K. McGuffie ${ }^{3}$, W. J. Riley ${ }^{4}$, G. A.

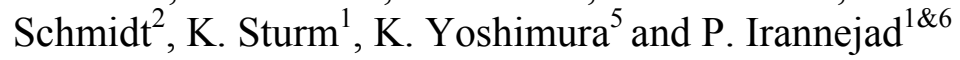

\begin{abstract}
${ }^{1}$ ANSTO, Institute for Nuclear Geophysiology, Menai, 2234, Australia
${ }^{2}$ NASA Goddard Institute for Space Sciences and Columbia University, New York, NY10025

${ }^{3}$ University of Technology, Sydney, Dept of Applied Physics, Sydney, 2007, Australia

${ }^{4}$ LBNL, Earth Sciences Division, Berkeley, CA97420, United States

${ }^{5}$ University of Tokyo, Tokyo, 153-8505, Japan

${ }^{6}$ University of Tehran, Institute of Geophysics, 6466-14155, Iran
\end{abstract}

Revised 31 Oct 2005

Re-revised 15 November 2005

Accepted for publication 20 November 2005

Address for correspondence

Dr M. Fischer

Institute for Nuclear Geophysiology

Australian Nuclear Science and Technology Organisation

Lucas Heights Science and Technology Centre

Private Mail Bag 1

Menai

NSW 2234

Australia

Emailipilps@ansto.gov.au 


\section{Abstract}

Phase 1 of isotopes in the Project for Intercomparison of Land-surface Parameterization Schemes (iPILPS) compares the simulation of two stable water isotopologues $\left({ }^{1} \mathrm{H}_{2}{ }^{18} \mathrm{O}\right.$ and $\left.{ }^{1} \mathrm{H}^{2} \mathrm{H}^{16} \mathrm{O}\right)$ at the land-atmosphere interface. The simulations are off-line, with forcing from an isotopically enabled regional model for three locations selected to offer contrasting climates and ecotypes: an evergreen tropical forest, a sclerophyll eucalypt forest and a mixed deciduous wood. Here we report on the experimental framework, the quality control undertaken on the simulation results and the method of intercomparisons employed. The small number of available isotopically-enabled land-surface schemes (ILSSs) limits the drawing of strong conclusions but, despite this, there is shown to be benefit in undertaking this type of isotopic intercomparison. Although validation of isotopic simulations at the land surface must await more, and much more complete, observational campaigns, we find that the empirically-based Craig-Gordon parameterization (of isotopic fractionation during evaporation) gives adequately realistic isotopic simulations when incorporated in a wide range of land-surface codes. By introducing two new tools for understanding isotopic variability from the land surface, the Isotope Transfer Function and the iPILPS plot, we show that different hydrological parameterizations cause very different isotopic responses. We show that ILSS-simulated isotopic equilibrium is independent of the total water and energy budget (with respect to both equilibration time and state), but interestingly the partitioning of available energy and water is a function of the models' complexity.

Keywords: water isotopes; land parameterisation; model intercomparison; CraigGordon scheme; PILPS 


\section{1. iPILPS Introduction}

\subsection{Background and Timing}

The goals of iPILPS are to (i) offer a framework for inter-comparison of isotopeenabled land-surface schemes (ILSSs) and (ii) encourage improvement of these schemes by evaluation against high quality (isotope) observations. When iPILPS was approved by the GEWEX Land-Atmosphere System Study (GLASS) in September 2004 (Henderson-Sellers, 2006), it was agreed that its first stage (Phase 1) would focus on the stable water isotopes $\mathrm{H}_{2}{ }^{18} \mathrm{O}$ and ${ }^{1} \mathrm{H}^{2} \mathrm{H}^{16} \mathrm{O}$.

Phase 1 of this international project tests the hypothesis that: Observation and analysis of the diurnal fluxes of ${ }^{1} \mathrm{H}_{2}{ }^{18} \mathrm{O}$ and ${ }^{1} \mathrm{H}^{2} \mathrm{H}^{16} \mathrm{O}$ between the soil, plants and atmosphere can accurately determine the partitioning of precipitation into transpiration, evaporation and total runoff (surface plus soil drainage). Although this hypothesis is not fully tested in this paper, the direction such testing could take is described in Henderson-Sellers (2006). The iPILPS effort will contribute (i) to improving the accuracy with which land-surface schemes partition net available surface energy into latent and sensible heat fluxes and thus (ii) to decreasing uncertainty in hydro-climate modelling and water resource vulnerability predictions. Phase 1 of iPILPS exploits novel stable water isotopes (SWI) and analysis techniques in the development and evaluation of ILSSs. To achieve the project aims, it is necessary to:

1. identify and test ILSSs which already (or plan soon to) incorporate SWIs;

2. appraise SWI data applicable to hydro-climatic and water resource aspects of ILSSs;

3. identify observational data gaps required for evaluating ILSSs and resolve them; and 
4. apply SWI data to specific predictions of well understood locations simulated by available ILSSs.

The timeline for Phase 1 of iPILPS began in late 2004 with the distribution of the Phase 1 plan and call for participants (see Henderson-Sellers, 2006). The simulations were conducted over the period February to April 2005. The inaugural iPILPS Workshop from 18 to 22 April 2005 was held in Sydney and focussed on the first intercomparison results. Throughout Phase 1 of iPILPS, an interactive website is being used to manage the ILSS simulations from participants (http://ipilps.ansto.gov.au). This allows quick-look intercomparisons by the ILSS owners and rapid community-wide dissemination of results.

\subsection{Forcing Meteorology and Isotopes}

Offline simulations need appropriate boundary conditions. The ILSSs require either measured forcing meteorology and isotopes or the same variables derived from a model representing atmospheric and isotopic processes as closely as possible to actual meteorological conditions. The meteorological and isotopic variables need to be coherent; deriving one from observations and the other from a model is not adequate.

For iPILPS Phase 1, it was determined that the only way of supplying adequately good forcing was to use an isotope-enabled atmospheric model. The REMO (REgionales MOdel, developed by the Max Planck Institute for Meteorology, Hamburg) had been shown to generate high quality simulations for two of the three selected locations (Sturm et al., 2005a,b). The spatial resolution of REMO is $1 / 2$ degree $(\sim 54 \mathrm{~km})$ with a model timestep of 5 minutes. REMO is nested into the 
European Centre Hamburg GCM (ECHAM) and the iPILPS Phase 1 forcings were derived from nesting into the 'climatological' version of ECHAM, which had a constant annual cycle in sea-surface temperatures - see Fischer and Sturm (2006) for further details.

Even though weather systems are better represented in REMOiso than in a global model, running in a climatological mode does not permit reproduction of specific meteorological situations. Global reanalyses, which assimilate all available meteorological observations, are believed to provide the best estimation of the actual state of the atmosphere (e.g. Kistler et al., 2001), but no isotopic information is yet available in any reanalysis.

The simulations of REMOiso have been thoroughly analysed in its first domain, which covers the European continent, encompassing temperate, Mediterranean and subpolar climates (Sturm et al., 2005a). Following this success, REMOiso was moved to the South American continent, including the Amazon, the arid grassland regions such as Brazil's Nordeste, and the Andes glaciers (Sturm et al., 2005b). Most recently, REMOiso has been integrated over Australia spanning tropical monsoons in the north, the arid centre and to Mediterranean climates in the south (Fischer and Sturm, 2006). All these model evaluations have been successful for simulated precipitation and humidities and their isotopic signature and REMOiso parameterizations have been proved to be elaborate enough to adequately represent secondary effects such as the deuterium excess. Based on these experiments, we are confident that REMOiso performs well in all climatic environments selected for iPILPS. 
The forcing data include magnitudes of each isotope (i.e. ${ }^{1} \mathrm{H}_{2}{ }^{18} \mathrm{O}$ and ${ }^{1} \mathrm{H}^{2} \mathrm{H}^{16} \mathrm{O}$ ) in precipitation and in water vapour at the atmospheric lowest level plus all the standard (ALMA - Assistance for Land surface Modelling Activities) meteorological forcing including 'regular' water $\left({ }^{1} \mathrm{H}_{2}{ }^{16} \mathrm{O}\right)$. Full details of the generation of these forcing data are given in Fischer and Sturm (2006) who also offer demonstrations that the simulations of REMOiso are of high quality.

\subsection{Participating ILSSs}

By the date of the first Phase 1 Workshop (April, 2005), five ILSSs had submitted simulations to the iPILPS web. Three other ILSSs were represented at the Workshop even though their simulations were not yet available. In this paper, results from the first five ILSSs only are compared, although the methodology used and recommended for future intercomparisons was derived with a broader ILSS community in mind. The five ILSSs whose simulations are included here are:

i) The REMOiso ILSS (Sturm et al., 2005a)

ii) The GISS ILSS (Aleinov and Schmidt, 2006)

iii) Iso-MATSIRO (Yoshimura, 2006)

iv) ICHASM (Fischer, 2006)

v) ISOLSM (Riley et al., 2002)

In all the intercomparisons presented here, these ILSSs are designated by a consistent letter (A-E). Note that the same letter always refers to the same model, but we do not reveal which of the models is letter "A", for example. This anonymity is intentionally used to focus analysis on the strengths and weaknesses of the whole group of simulations rather than specific models. Naturally, all ILSS owners are 
aware of their model's performance and some aspects of these are described in detail in the papers in this volume listed above.

\section{Experimental Plan for Phase 1}

\subsection{Outline}

It was planned to undertake iPILPS ILSS' evaluation in two stages, each with two parts:

(i) spin-up and conservation check simulations:

(a) gross water and energy

(b) stable water isotopologues (SWIs): ${ }^{1} \mathrm{H}_{2}{ }^{18} \mathrm{O},{ }^{1} \mathrm{H}^{2} \mathrm{H}^{16} \mathrm{O},{ }^{1} \mathrm{H}_{2}{ }^{16} \mathrm{O}$

and

(ii) comparison and evaluation with observations:

(a) monthly means and annual cycles

(b) diurnally resolved simulations.

Although the main aim of iPILPS Phase 1 is ILSS simulations' intercomparison, sites for simulation have been selected which cover a range of climatologies, and for which there are high resolution meteorological and some isotopic observations available. Unfortunately, it has proved impossible to identify diurnal isotopic observations of high enough quality to add value, although this study has prompted a recent Australian campaign in Tumbarumba (Twining et al., 2006).

The three selected locations for iPILPS Phase 1 are:

(i) Mid-latitude (deciduous) grass/woods, nominally at Munich $48^{\circ} \mathrm{N} 11^{\circ} \mathrm{E}$

(ii) Tropical (evergreen) rainforest, nominally at Manaus $3^{\circ} \mathrm{S} 60^{\circ} \mathrm{W}$ 
(iii) Mid-latitude eucalypt (evergreen) forest, nominally at Tumbarumba $35^{\circ} \mathrm{S} 148^{\circ} \mathrm{E}$. A general description of the geo-ecology and climatology of each location is provided on the iPILPS website (http://ipilps.ansto.gov.au). Forcing was provided for the three locations for four years. The experimental design directed each ILSS to use the first year's forcing repeatedly for as many years as that ILSS required to achieve equilibrium (this experimental component was designated EQY1), and then use the next three years' forcing to create three years' simulations (this 'Basin Comparison' was designated $\mathrm{BC} 24)$.

\subsubsection{Equilibration Experiment (EQY1)}

Each ILSS initialized water reservoirs at half capacity (except snow capacity, which is infinite in all participating schemes, and hence initialised with zero $\mathrm{H}_{2} \mathrm{O}$ ), all water isotope reservoirs at VSMOW, and all temperatures at the supplied annual mean surface air temperature. Then the REMOiso Year 1 forcing was applied over as many repeated years as required to reach equilibrium. Equilibrium was defined as in PILPS 2a (Cabauw - see Chen et al., 1997). That is, for bulk water and energy, equilibrium was defined as being the first occasion on which the January mean values of surface radiative temperature, latent and sensible heat fluxes, and rootzone soil moisture did not change by more than $0.01 \mathrm{~K}, 0.1 \mathrm{~W} \mathrm{~m}^{-2}$ and $0.1 \mathrm{~kg} \mathrm{~m}^{-2}$, respectively, from year $N$ to year $N+1$. The equilibration time was then $N$ years.

In this first iPILPS experiment, no criteria were specified for isotopic equilibrium, but some model owners applied their own criteria (that is, that the isotopologue mass changes were less than a sufficiently small, but generally arbitrary, value). The main goal of EQY1 was setup and equilibration to ensure gross water and energy 
conservation but the design allowed a secondary goal: the determination of spin-up times and trajectories for SWIs, once the gross water mean state was confirmed as equilibrated.

\subsubsection{Grid-point/Site Scale Comparison (and ultimately Evaluation)} (BC24)

For each ILSS, the REMOiso years' 2 to 4 were applied sequentially starting from the conditions achieved after EQY1. For this experimental component, the planned goal was site-specific diurnal comparison and also evaluation against available observational data. Following exhaustive searches, it has been determined that no diurnal observations of adequate quality exist for these locations. At this time, the analysis is therefore limited to ILSS intercomparison. However, it is hoped to undertake monthly mean basin-scale comparison and evaluation against observations from Global Network for Isotopes in Precipitation (GNIP) and the Global Network for Isotopes in Rivers (GNIR) programmes.

\subsection{Data Protocols}

\subsubsection{ALMA (Assistance for Land-surface Modelling Activities)}

As part of GLASS's PILPS, iPILPS uses the ALMA convention for variable names, units and signs (http://www.lmd.jussieu.fr/ p polcher/ALMA/convention_3.html). We opted to use ALMA's 'Traditional' format for model output (http://www.lmd. jussieu.fr/ p polcher/ALMA/convention_output_3.html).

As many variables, especially the isotopic ratios, did not have existing ALMA conventions, we extended the ALMA conventions to include new variable names. 
Some of these new variable names are based on the NCEP/NCAR Reanalysis data conventions: http:/www.cdc.noaa.gov/cdc/data.ncep.reanalysis.html. The new variables are listed in Tables 1 and 2.

\subsection{Model Forcing and Model Output}

The model forcing described here includes both atmospheric forcing and timeinvariant surface properties. The time-invariant surface properties likely to be needed for each location simulated, such as vegetation type specifications and soil property specifications, were provided and are listed in Table 3.

The forcing variables for iPILPS Phase 2 experiments provided by the Regional Isotope Model (REMOiso) are listed in Table 1. The forcing data has a length of four years and a timestep of 15 minutes. If any ILSS operated at a different temporal resolution, the forcing data was either averaged or interpolated. The forcing data from REMOiso were checked, as far as possible, against NCEP reanalysis data, and hourly discontinuities were noticed in the radiation data. To remove these, the downward shortwave and longwave radiation were smoothed using a uniform weighted filter with a window width of two hours.

Unfortunately, we could not obtain separate streams of direct and diffuse solar radiation at the surface nor the visual (VIS) and near-infrared (NIR) proportions of the downward shortwave radiation from REMOiso. For the VIS/NIR we used a 50:50 split of downward shortwave radiation. In the absence of information from REMOiso on the partitioning between diffuse and direct irradiance, we elected to divide the 
global irradiance as $30 \%$ diffuse and $70 \%$ direct for all three locations. This approximation seems justified since under clear skies diffuse radiation comprises around $10 \%$ of the global irradiance while, even for very cloud locations such as the Antarctic coast, the fraction of total global irradiance present as diffuse radiation is less than $50 \%$. Although this strategy limits the evaluation of aspects of simulated space (notably $100 \%$ diffuse under completely cloudy skies), it seemed prudent in this first phase of iPILPS to avoid the introduction of another set of variables and parameters associated with empirical schemes for derivation of diffuse and direct irradiance. The authors are aware of the inadequacy of this assumption when the accurate estimation of diffuse radiation is important, but only one ILSS (C) required these extra radiation variables. Improvements to the derivation of extra radiation forcing will be made in future iPILPS experiments.

The above experimental plan was not followed for the model labelled Model E (in this document), which reported results from on-line GCM experiments which were fully enabled with isotopic tracers. Several years of output for the variables in Table 3 were obtained from these on-line runs (using 365-day years) for the three experimental locations. Hence, the forcing for the ILSS E was different from the prescribed iPILPS forcing data. The resulting differences are discussed further below.

Although BC24 simulations were submitted and are available on the iPILPS web, this paper, in line with the Workshop, focuses exclusively on the equilibration year: EQY1. 


\section{Intercomparison of iPILPS Simulations}

The Workshop established its goals as: To demonstrate that isotopically-enabled Land Surface Schemes (ILSSs) generate plausible simulations at the diurnal scale of the exchanges of Stable Water Isotopes (SWIs) at the soil, plant, air interfaces or to identify their shortcomings and propose ways of improving the simulations. The specific questions for discussion at the iPILPS Workshop were:

a) are simulation differences due to (i) sensitivity to forcing; (ii) parameterization differences; (iii) both?

b) is the Craig \& Gordon (1965) isotope evaporation model 'adequate' for use in ILSSs and, if not, what is required? and

c) on diurnal scales how large are SWI differences; what observations could illuminate 'adequacy'?

It was quickly determined that there is little, or no, point in analysing SWI simulation results if the ILSSs are inadequate from the point of view of: i) conservation of energy and water; and ii) adequacy of the gross fluxes of energy and water. We therefore reviewed these first using methods developed in PILPS (e.g. Chen et al., 1997). Although some energy and moisture balance problems remain in ILSSs B and C (Figures 1 and 2), several variables for these ILSSs have been plotted, simply for comparison purposes. Given the remaining errors, the simulation outputs of these ILSSs must be currently interpreted carefully. Many participants have found this intercomparison project to be a valuable exercise and, as a result, the participants have been or currently are, working to improve their models in many areas, including conservation (discussed below). 


\subsection{Energy and Gross Water Simulations for EQY1}

In the following sections, the overall conservation in the annual energy and water budgets is examined, as well as variations on monthly and diurnal timescales. Secondly, the effect of model complexity on the annual budgets is explored using the "PILPS plot" developed during the early PILPS experiments. Thirdly, isotopic fluxes at monthly and diurnal timescales are investigated, and a new graphic representation is introduced for the iPILPS model intercomparison.

\subsubsection{Conservation}

\section{Annual}

Outputs from all schemes were checked to ensure the conservation of bulk energy and water over the equilibrium year. ILSSs A, B, D, and E all have annual means of energy and water fluxes such that:

$\mid$ Xnet - Qle - Qh $\mid<0.3 \mathrm{~W} \mathrm{~m}^{-2}$

$\mid \operatorname{Pr}-$ Evap $-\mathrm{Ro} \mid<3 \mathrm{~kg} \mathrm{~m}^{-2} \mathrm{yr}^{-1}$

where Xnet is net radiation, $\mathrm{W} \mathrm{m}^{-2}$, Qle is latent heat, $\mathrm{W} \mathrm{m}^{-2}, \mathrm{Qh}$ is sensible heat, $\mathrm{W} \mathrm{m} \mathrm{m}^{-2}, \operatorname{Pr}$ is precipitation, $\mathrm{kg} \mathrm{m}^{-2} \mathrm{yr}^{-1}$, Evap is total evapotranspiration, $\mathrm{kg} \mathrm{m}^{-2} \mathrm{yr}^{-1}$, and $R o$ is surface + subsurface runoff, $\mathrm{kg} \mathrm{m}^{-2} \mathrm{yr}^{-1}$. (Note that we use Table 2 radiation variable names but prefer the simpler terms for the water variables throughout the text). Note that the energy of precipitation is included in the Table 2 forcing variables, 
but we have neglected it in equation (1), as in previous PILPS experiments (e.g. Chen et al. 1997) because its value is small. The conservation threshold for the surface water budget is selected to be approximately equivalent to that for energy budget, based on the water-energy relationship through the latent heat of vaporisation.

\section{Monthly}

Similarly, outputs from all schemes were checked to ensure the conservation of bulk energy and water over months in the equilibrium year, EQY1.

The expected monthly surface energy balance is:

$X n t_{j}-Q l e_{j}-Q h_{j}-Q g_{j}=0$

where $j$ is the month index, and $Q g$ is the sum of the heat flux into the soil, canopy and snowpack. Because the canopy heat capacity is small, the vegetation heat flux can be ignored here.

The expected monthly water balance is:

$P r_{j}-\operatorname{Evap}_{j}-R o_{j}-\Delta S_{j}=0$

where $\Delta S_{j}$ is the change in the total storage water (soil, canopy, snowpack) for month $j$.

Figures 1-2 show the components of the energy and water budgets, for the 5 ILSSs, at a monthly timescale (these diagrams also show the seasonal cycle, discussed further 
below). The monthly energy budget (Figure 1) errors are $<|0.3| \mathrm{W} \mathrm{m}^{-2}$ for four models, but $<|15| \mathrm{W} \mathrm{m}^{-2}$ for $\mathrm{C}$ [some steps have been taken to correct this]. The monthly water budget (Figure 2) errors are generally $<|0.25| \mathrm{kg} \mathrm{m}^{-2} \mathrm{mon}^{-1}$. Model B is not included in the diagrams showing the runoff and evaporation variables because of inconsistencies in its output files. Evaporation in particular needed to be scaled by a fitting factor to be in the same order of magnitude as other components of the water budget. This requirement was traced to a bug in the code, relating to a missing time weighing factor in the output routine of this accumulated variable. Even this improvement is not sufficient to achieve the closure of ILSS B's water budget. Further investigation reveals that the incorrect evaporation fluxes are related to a diagnostic error, which does not significantly affect the soil water prognosis.

\subsubsection{Annual Means and Seasonal Cycles}

This paper examines only the differences between the models, rather than differences between the models and observational data. This is, in part, because of the climatological nature of the REMOiso forcing, and hence of the simulation and, in part, because of the lack of high temporal resolution observations.

The statistics for the components of annual energy and water budgets of the models are shown in Table 4 (note that all the models are used in calculating the median, minimum and maximum values below, but the median effectively moderates the importance of the most "outlying" model). For Tumbarumba, the "median model" (that is, the median values from the five ILSSs) partitions $\sim 96 \mathrm{~W} \mathrm{~m}^{-2}$ of net radiation into $\sim 15 \mathrm{~W} \mathrm{~m}^{-2}$ of sensible heat and $\sim 76 \mathrm{~W} \mathrm{~m}^{-2}$ of latent energy (note that the 
partitioning does not necessarily sum to the available energy due to partly the use of medians and partly because of non-closure of surface energy balance by the ILSSs). For Manaus, the "median model" partitions $\sim 151 \mathrm{~W} \mathrm{~m}^{-2}$ of net radiation into $\sim 28 \mathrm{~W}$ $\mathrm{m}^{-2}$ of sensible heat and $\sim 118 \mathrm{~W} \mathrm{~m}^{-2}$ of latent energy. For Munich, the "median model" partitions $\sim 58 \mathrm{~W} \mathrm{~m}^{-2}$ of net radiation into $\sim 6 \mathrm{~W} \mathrm{~m}^{-2}$ of sensible heat and $\sim 43$ $\mathrm{W} \mathrm{m}^{-2}$ of latent energy. More importantly, the inter-model variation in the sensible and latent heat values is large. The variation, shown as the total range, for sensible heat flux is $\sim 24,49$ and $43 \mathrm{~W} \mathrm{~m}^{-2}$ and for latent heat flux is 27,62 and $45 \mathrm{~W} \mathrm{~m}^{-2}$ for Tumbarumba, Manaus and Munich respectively.

The median annual water budgets are as follows. For Tumbarumba, the "median model" partitions $\sim 100 \mathrm{~kg} \mathrm{~m}^{-2}$ month $^{-1}$ of precipitation into $\sim 19 \mathrm{~kg} \mathrm{~m}^{-2} \mathrm{month}^{-1}$ of runoff and $\sim 73 \mathrm{~kg} \mathrm{~m}^{-2}$ month $^{-1}$ of evaporation. For Manaus, the "median model" partitions $\sim 264 \mathrm{~kg} \mathrm{~m}^{-2}$ month $^{-1}$ of precipitation into $\sim 96 \mathrm{~kg} \mathrm{~m}^{-2} \mathrm{month}^{-1}$ of runoff and $\sim 121 \mathrm{~kg} \mathrm{~m}^{-2}$ month $^{-1}$ of evaporation. For Munich, the "median model" partitions $\sim 93$ $\mathrm{kg} \mathrm{m}$ month $^{-1}$ of precipitation into $\sim 31 \mathrm{~kg} \mathrm{~m}^{-2}$ month $^{-1}$ of runoff and $\sim 42$ $\mathrm{kg} \mathrm{m}^{-2}$ month $^{-1}$ of evaporation. Again, more importantly, the variation between the models in the evaporation and runoff is large. This variation or total range (among the different ILSSs) is $>25,>45$ and $>45 \mathrm{~kg} \mathrm{~m}^{-2} \mathrm{month}^{-1}$ for Tumbarumba, Manaus and Munich respectively. The largest variations here are because Model E was run on-line, and hence received its forcing data from the atmospheric module of a GCM, different from REMOiso. This is evident in Figure 1(k), where Model E shows a seasonal cycle of the surface net radiation different from other models mainly because of different regimes of solar radiation incident at the surface. 
Comparing the values reported for Qle and Evap in Table 4 reveals an inconsistency in the models' outputs. For example, in the absence of snow/ice cover (e.g. Manaus), the relationship Qle $=\lambda \times$ Evap holds, where, $\lambda$, the latent heat of vaporisation is about 25.e5 $\mathrm{J} \mathrm{kg}^{-1}$ at zero degrees Celsius. Therefore, taking the maximum Evap of $142 \mathrm{~kg} \mathrm{~m}^{-2}$ month $^{-1}$ for Manaus, the maximum Qle should not exceed $135 \mathrm{~W} \mathrm{~m}^{-2}$, much smaller than the $156 \mathrm{~W} \mathrm{~m}^{-2}$ reported by the ILSSs. Such inter-model variation is due to either i) model behaviour, ii) unresolved errors in reporting model ouput or iii) both. There is no doubt that three ILSSs meet the energy balance criteria (and have been reported in the desired way: A, D and E, Figure 1 is proof of this). Any remaining problems with the ILSSs can only be solved by individual model owners (with the help of the iPILPS team).

The seasonal cycles can also be seen in Figures 1 and 2. The expected seasonal cycles are replicated for Munich and Tumbarumba. The expected increase in runoff in the Manaus wet season (December-February) is also shown by all models except E, probably due to the very different seasonal cycle of precipitation used by E (see Figure 2a).

\subsubsection{Diurnal Cycles}

Figures 3-8 show the components of the energy and water budgets, for the 5 ILSSs, with hourly resolution constructed by averaging all the days in January and July (again, the five models are designated by letter and line type).

\section{Energy Budget}


The shape of the diurnal cycle of the net radiation is generally similar for each model (but different between the locations). More noticeably, the variation between different models is of the order of $10^{1}-10^{2} \mathrm{~W} \mathrm{~m}^{-2}$. The variation in the main components of net radiation (that is, sensible and latent heat fluxes) is as large or even larger. Similar to the case of seasonal cycle, Model E simulates the diurnal cycle of net radiation differently from the other models. Compared to other ILSSs, E simulates the highest daytime surface net radiation in January and lowest in July, with a tendency of losing more surface energy at night. (Figure $3 \mathrm{a}, \mathrm{e}$ ). Given the similar solar zenith angles for January and July in Manaus, one expects that the diurnal cycles of net radiation be similar for the two months. This is correct for the four ILSSs forced by REMOiso, but the coupled Model E shows the diurnal cycles of net radiation for the two days that are too different in magnitude to be correct for a site close to the Equator.

The partitioning of the surface net radiation between Qh and Qle in the two months is very different for Model A, which shows much lower Qle and higher Qh than other models in July. This could be the result of oversensitivity of A's evaporation to precipitation, problem with transpiration modelling (see Figure $6(\mathrm{~g})$ ) or errors in output files. Model A also simulates too high sensible heat flux from the atmosphere to the surface and too high latent heat flux from the surface during the night in July and throughout the day in January in Munich (Figure 4). Considering the fact that air temperature and humidity for the simulations are prescribed (by REMOiso), such results should arise from Model A having a too low surface temperature and too high surface air humidity (a function of surface available moisture and surface temperature -- in contradiction with the expected low temperature). It also might be that $\mathrm{A}$ has a 
problem of too little resistance to boundary layer fluxes, when the atmosphere is in stable conditions (during nights and the cold season). In Model C, for Tumbarumba, the latent heat flux on an average January day is $\sim 100 \mathrm{~W} \mathrm{~m}^{-2}$ less than the other models (Figure 5). The phase of the energy components also differs widely between the different models. For example, the peaks in latent heat and ground heat flux generally occur earlier in Models E and D than C, but this is not always the case (for example, Munich in January, Figure 4). Thorough investigation needed by the modelling groups to identify the cause(s) of these model misbehaviours. The purpose of this paper is to focus mainly on the isotope differences, and how these are linked to atmospheric forcing and model structure.

\section{Water Budget}

The precipitation is the same for each model (for a particular location) because it is prescribed, except for Model E (the online GCM run). Hence there are only 2 lines for precipitation in Figures 6-8. However, the variation in the components of the water budget on the diurnal timescale is again very large. For example, for Manaus, Models A, C and D show similar patterns of evaporation and run-off, but very different transpiration patterns (Figure 6). The phase of transpiration also differs between the ILSSs, according to location and season. For Munich and Tumbarumba, all models show very different patterns of runoff, evaporation and transpiration (Figures 7 and 8). There does not seem to be any consistency in the models' relative behaviour at these sites: each model responds to the time-invariant surface properties and forcing data for each location in complex ways. 


\subsection{PILPS Plots}

Figure 9 shows the annual mean sensible and latent heat (and annual mean runoff and evaporation) plotted against each other for the five ILSSs (designated by letter; here the line type refers to the different sites: Manaus, Munich, Tumbarumba). The different models should roughly scatter along lines having a slope of -1 and have intercepts equal to the mean model net radiation $($ Xnet $=Q l e+Q h)$. The energy graph (Figure 9a) has been further scaled by

$$
\begin{aligned}
& \text { new } Q l e_{m}=Q l e_{m}(\overline{\text { Xnet }})\left(\text { Xnet }_{m}\right)^{-1} \\
& \text { new } Q h_{m}=Q h_{m}(\overline{\text { Xnet }})\left(\text { Xnet }_{m}\right)^{-1}
\end{aligned}
$$

where $\overline{X n e t}=$ mean annual $\left(Q_{l e}+Q_{h}\right)$ of all models (for a particular site) and $X_{n e t_{m}}=$ mean annual $\left(Q_{l e}+Q_{h}\right)$ for a particular model $m$.

This scaling is necessary because $X_{n e t}$ is different for each model (especially E, the online GCM run). A similar scaling (but with precipitation instead of radiation) applies to the runoff/evaporation plot (Figure 9b). The position of the ILSS letters in Figure 9 shows the overall annual proportion of the major components that comprise the energy and moisture budgets. It is possible for two models to have a similar overall annual budget in energy or moisture, but a significant difference between the two models in how the components of the energy or moisture budget are distributed throughout the year. (These plots do not show how the energy and water is partitioned during different months through the year). 
As in the earlier PILPS analyses, the ILSSs are roughly positioned on the basis of their complexity (e.g. Henderson-Sellers et al., 2003), although the number of ILSSs examined here is too small to derive a firm conclusion the Bucket land-schemes follow the land-surface parameterization of Manabe (1969), while the soil-vegetationatmosphere transfer models (SVATs) use 1980s' parameterization (for example, Sellers et al. (1986), Dickinson et al. (1986)). Here, the complexity of ILSSs A, B, C, D and E corresponds to a A) SVAT, B) Bucket, C) a complex SVAT, D) SVAT/Bucket and E) SVAT (a complex SVAT means a third generation LSM [Land surface model], see Pitman (2003); while SVAT/Bucket means the model is parameterised in a way that falls somewhere between these two types of parameterizations) (see also Rozenweig and Abramopoulos, 1997; Desborough, 1999; Riley et al., 2002; Takata et al., 2003). Figure 9 shows that the ILSSs roughly plot according to their complexity. For example, ILSS E (SVAT) generally has a relatively high Qh:Qle ratio, while ILSS B (which has a Bucket hydrology) has a relatively low Qh:Qle ratio; this distribution of complexity agrees with earlier PILPS analyses (e.g. Pitman et al., 1999). ILSS D is found somewhere in the middle: it is a Bucket land-scheme, but with additional bare ground and stomatal resistances. ILSSs $\mathrm{A}$ and $\mathrm{C}$ show differing behaviours between the three simulated locations (the complexity of these ILSSs makes the actual reasons for variance difficult to establish).

The patterns in the runoff/evaporation plot are less clear (Figure 9b). The different behaviour of ILSS E is probably due to the very different rainfall forcing in the online GCM run. ILSS D generally falls between ILSS A and C, but again ILSS A and C 
show complex behaviour (ILSS B has been removed from this plot due to the unexplained error in its hydrology files).

\section{Stable Water Isotope Simulations for EQY1}

\subsection{Annual Means and Seasonal Cycles of SWIs}

Figure 10 shows the seasonal cycles of monthly (weighted) $\delta$ values for the ${ }^{18} \mathrm{O}$ isotope (note that in the remainder of this paper, $\delta$ without subscript refers to either isotopologue). Note that the term $\Delta \delta S$ represents the change in the isotopic content of all water storage reservoirs (snowpack, canopy, soilwater) between the start and end of a month. This $\delta$ value of small water fluxes may be poorly calculated because of round-off errors but should approximate zero. However, as iPILPS did not require participants to provide isotopic information for all the reservoirs (e.g. snowpack) even though most did, any unexpected values could be due to incomplete reporting.

There are two expectations for SWIs: i) at small intervals of time, $\delta$ runoff should equal $\delta$ precipitation, and ii) at longer timescales, variations of $\delta$ in Evap and Ro might be similar to those of $P r$, because Evap and $R o$ may result from a combination of multiple $\mathrm{Pr}$ events in previous days. On the monthly timescale, ILSSs $\mathrm{A}$ and $\mathrm{C}$ show $\delta E v a p$ and $\delta R o$ patterns that are similar. In the case of Munich, where $\delta P r$ is similar for ILSSs A-D and E, ILSSs D and E also show similar trends in $\delta R o$ and $\delta$ Evap, except in the summer (May-September) months when there is no runoff in ILSS D (Figure 10). Given these similarities between the models, it is unlikely that the ILSS ouput diverges from the two expectations above due to 
inadequate structure in the models (i.e. it is very unlikely that the different schemes have been coded poorly in the same way). Some possible reasons for the similarities and differences in isotope patterns are discussed in Section 4.2. A more detailed understanding of the monthly isotope balance may be obtained by "adding isotopes" to the monthly water balance model of Koster and Milly (1997). This will be the topic of a future paper.

\subsection{Diurnal Cycles of SWIs}

The diurnal cycles of isotopes for the water budget components are shown in Figures 11-13 ( $\delta^{18} \mathrm{O}$ only). Showing the $\delta^{18} \mathrm{O}$ for these components provides a baseline for understanding the isotope signal: the $\delta^{2} \mathrm{H}$ are not shown because they are simply shifted from the $\delta^{18} \mathrm{O}$ according to some ratio (and thus show the same monthly/diurnal pattern). However, both isotopes appear on the iPILPS website http://ipilps.ansto.gov.au/ and the $\delta^{18} \mathrm{O}: \delta^{2} \mathrm{H}$ ratios are shown in later plots (Figures 1517).

Isotope values are averaged for each hour (using weighted averages) over 30 days in two different months (January and July). At this scale of aggregation, $\delta$ Ro values are seen not to match the precipitation $(\mathrm{Pr})$. The reason for this is the selection of rainfall events i.e. some rainfall 'events' are selected for infiltration, while others are selected for runoff, even at the same hour of day in a single month. This means that the weighted isotopic composition of the rainfall and the weighted isotopic composition of the runoff, averaged at the hourly timescale over a single month, do not have to 
match. The same applies to longer timescales, and probably increases the disparity between simulated isotopic composition of runoff and precipitation.

This 'event selection' concept is also applicable to non-plant evaporation (Ev) and to transpiration $(\mathrm{Tr})$. While the bulk evaporation and transpiration trends may be similar over the daily cycle, changes in the proportion of evaporation and transpiration over the daily cycle effectively changes the soil moisture depth that is being sampled. Hence, over some scale of averaging, the soil water sampled by evapotranspiration does not have to have the same isotopic composition as that of the bulk soil water (over the same depth) averaged over the same timescale. Given that, so far, all the participating ILSSs use a Craig-Gordon parameterization for evaporation, the differences in the isotopic budgets in different ILSSs is probably largely due to the selection and mixing processes. (Although the Craig-Gordon (1965) isotope evaporation model has been modified by several authors (e.g. Gonfiantini, 1986; Mathieu and Bariac, 1996), the use of modified equations in ILSS sensitivity has yet to be tested.) This recognition has prompted the creation of the Isotope Transfer Function (ITF), which can be written as:

$\delta_{\text {reservoir }}=\boldsymbol{f}$ (mixing, selection, isotope fractionation)

That is, the $\delta$ value of a storage reservoir is a function of the selection of inputs into the reservoir, how those inputs are mixed with the reservoir, and the fractionation that may occur when water is lost from the reservoir. Here, this function is discussed qualitatively, but it can be made quantitative through various statistical approaches (see below). Selection processes control which rainfall events and soil water are 
selected for runoff and for total evapotranspiration (Evap) and, indeed, for its components, Ev and Tr. In addition, all the land-schemes have different mixing processes (i.e. how the rainfall and different soil reservoirs are mixed together when there is movement of water from one soil layer to another differs between the ILSSs). An advantage of investigating simulations by isotope-enabled land-surface schemes is that the isotopes can be used to understand the effect of these selection and mixing processes on water budgets. Although this has not been shown explicitly here, the different effects on isotopic fluxes of different mixing schemes can be seen in the ILSS papers included in this issue. One further method of analysing this might be to compare the different ILSSs by statistically fitting and plotting the convolution functions of the first two processes (mixing and selection), similar to the approach used in Weiler et al. (2003). Resulting information about the impact of parameterization choices on water budget and flux characterisation cannot be easily derived from an LSS that does not have isotopic tracers.

\subsection{Analysis of ILSS Simulations of SWIS}

This section introduces a new PILPS-style plot for the evaluation of ILSSs.

The expected monthly isotope mass balance is (to a good approximation):

$$
\left(\delta \operatorname{Pr}_{j} * \operatorname{Pr}_{j}\right)-\left(\delta E v a p_{j} * E v a p_{j}\right)-\left(\delta R o_{j}^{*} R o_{j}\right)-\left(\delta \Delta S_{j}^{*} \Delta S_{j}\right)=0
$$

where, $\delta \operatorname{Pr}_{j}$ is the monthly (weighted) isotope $\delta$ value of precipitation (relative to $\mathrm{VSMOW}$ ); $\delta \mathrm{Evap}_{j}$ is the monthly (weighted) isotope $\delta$ value of evaporation (relative to VSMOW); $\delta \mathrm{Ro}_{j}$ is the monthly (weighted) isotope $\delta$ value of surface plus 
subsurface runoff (relative to VSMOW); and $\delta \Delta S_{j}$ is the monthly (weighted) isotope $\delta$ value of the change in the total storage water (relative to VSMOW). Note that, for Equation (8), the error introduced by conversion to delta values is $<0.3 \%$ over the natural range of delta values. The storage term will be zero over the entire year, for the equilibrium year (note that the year must be in isotopic equilibrium). The expected annual mass balance is then:

$$
\overline{\delta P r}=\frac{\overline{E v a p}}{\overline{P r}}\left(\frac{\sum_{\text {all } j}\left(\delta \operatorname{Evap}_{j}{ }^{*} \text { Evap }_{j}\right)}{\sum_{\text {all } j} \operatorname{Evap}_{j}}\right)+\frac{\overline{\operatorname{Ro}}}{\overline{\operatorname{Pr}}}\left(\frac{\sum_{\text {all } j}\left(\delta R o_{j} * R o_{j}\right)}{\sum_{\text {all } j} R o_{j}}\right)
$$

where $\overline{\delta P r}$ is the weighted mean monthly $\delta$ precipitation value, $\overline{E v a p}$ is the mean monthly evaporation, $\overline{R o}$ is the mean monthly surface + subsurface runoff and $\overline{\mathrm{Pr}}$ is the mean monthly precipitation.

Plotting the two terms on the right-hand side of Equation (9) against each other generates a plot with an intercept of $\overline{\delta P r}$ and a slope of -1 . The plot can also be scaled to take into account the situation where ILSSs are forced by rainfall with different annual $\overline{\delta P r}$ with the two variables scaled as follows.

$$
\begin{aligned}
& \text { new } \delta \operatorname{Ro}_{m}=\delta \operatorname{Ro}(\overline{\overline{\delta P r}})\left(\overline{\delta P r}_{m}\right)^{-1} \\
& \text { new } \delta \operatorname{Evap}_{m}=\delta \operatorname{Evap}_{m}(\overline{\overline{\delta P r}})\left(\overline{\delta P r}_{m}\right)^{-1}
\end{aligned}
$$


where $\overline{\overline{\delta P r}}$ is the mean monthly $\delta$ precipitation of all ILSSs (for a particular site) and $\overline{\delta P r}_{m}$ is the weighted mean monthly $\delta$ precipitation for a particular ILSS $m$.

The plot for the EQY1 experiments (produced using Equation 9, with no additional scaling) is shown in Figure 14a for Manaus, Tumbarumba and Munich (the ILSSs are designated by letters). The axes in Figure $14 \mathrm{a}$ are $(\overline{\operatorname{Evap}} / \overline{\operatorname{Pr}}) \delta$ Evap and $(\overline{R o} / \overline{\operatorname{Pr}}) \delta R o$. A similar plot to Figure $9 \mathrm{~b}$, but produced using the mass amounts of $\mathrm{H}_{2}{ }^{18} \mathrm{O}$ is shown in Figure 14b. The axes in Figure $14 \mathrm{~b}$ are the scaled mass amounts of $\mathrm{H}_{2}{ }^{18} \mathrm{O}$ in total evaporation and runoff (the expected intercept of the lines in Figure $14 \mathrm{~b}$ is the mass amount of $\mathrm{H}_{2}{ }^{18} \mathrm{O}$ in 12-month mean precipitation). In these plots, ILSS E falls close to the line in Figure $14 \mathrm{~b}$ but not Figure 14a because although its $\mathrm{H}_{2}{ }^{18} \mathrm{O}$ mass is similar to that of the other models, the associated amount of $\mathrm{H}_{2}{ }^{16} \mathrm{O}$ is not. ILSSs A and C have similar fractionation processes in both bulk amount and isotopes in Tumbarumba and Munich, but different in Manaus. In Manaus, ILSS A has more runoff (hence greater $\mathrm{H}_{2}{ }^{18} \mathrm{O}$ mass), but isotopic fractionation is for some reason different (since they both end up with similar weighted $\delta$ amounts for evaporation and runoff). This requires a closer investigation at the individual storm scale (beyond the scope of this paper).

Further, Figure 14a demonstrates the intricate relationship between transpiration, soil evaporation, runoff, rainfall event selection, and their isotopic signature. It is important to note here that transpiration is generally thought to be more isotopically enriched than soil evaporation (e.g. see Gat (1996) and also Section 4.4 below). Imagine that a single ILSS has a certain soil evaporation, transpiration and runoff 
partitioning. If the parameters of the evaporation and transpiration $(\mathrm{Tr})$ parameterisation were changed in such a way that the total evapotranspiration (Evap) did not change, but that the $\operatorname{Tr} /$ Evap ratio did, then it might be expected that the SEvap signal would shift along the horizontal axis according to whether there was more or less transpiration. However, a model in isotopic equilibrium has to also shift along the site's line of equilibrium. In the case of the above scenario (where there is a change in Tr/Evap but no bulk change in Evap), the shift along the line of equilibrium can only happen if the rainfall event selection processes change in such a way that the isotopic content of the runoff (and infiltration) changes appropriately. In other words, if $\operatorname{Tr}$ Evap becomes larger (with no bulk change in Evap) then the rainfall event selection processes (which partition the isotopes in runoff and infiltration) must become greater (more isotopically depeleted runoff) in order to compensate for the isotopic shift due to increased transpiration. Hence, the $\operatorname{Tr} /$ Evap ratio is important in determining how runoff is selected from rainfall.

This apparently straightforward conclusion cannot be drawn from standard LSS analyses of runoff versus evaporation. For example, in a PILPS plot (e.g. Figure 9), there is no indication that a change in $\operatorname{Tr} /$ Evap forces a change in how runoff is selected from rainfall events. Hence, isotopes provide a new diagnostic for land surface models that is intricately related to land surface processes. Further, this new diagram (Figure 14a) is a conceptual diagram that gives a quick summary of the annual isotope mass balance, just as the PILPS sensible and latent heat plot is a quick summary of the annual total energy budget. This new "iPILPS plot" should be a useful tool in all isotope-enabled model intercomparisons of simulations of surfaceatmosphere exchanges. 


\section{$4.4 \delta^{18} \mathrm{O}: \delta^{2} \mathrm{H}$ plots}

Figures 15-17 show monthly $\delta^{18} \mathrm{O}: \delta^{2} \mathrm{H}$ plots for the components of moisture budget (ILSSs are designated by letters). The linear scatter shows that the monthly pattern of $\delta^{2} \mathrm{H}$ is the same as $\delta^{18} \mathrm{O}$. The $\delta^{18} \mathrm{O}: \delta^{2} \mathrm{H}$ ratio, however, is different between different ILSSs (except precipitation for ILSSs A-D since these all use the same, prescribed, forcing data). The precipitation from both the online GCM run (ILSS E here) and REMOiso forcing fall along the Global Meteoric Water Line, $\delta^{2} \mathrm{H}=8 * \delta^{18} \mathrm{O}+10$ (the GMWL is the diagonal line in Figures 15-17). The change in the isotopic content of the storage reservoirs (snowpack, soil water, canopy water) is generally small $(\sim 0)$ for all ILSSs except D. This suggests that for this ILSS the soil reservoir (which makes up the major component of total storage) has a very different size and residence time than the soil reservoir in the other ILSSs (which may contribute to a longer time necessary to reach isotopic equilibrium). These diagrams suggest that isotopes also have the potential to be valuable tools for learning about water residence times in land-surface schemes: features which cannot be easily achieved in LSMs without an isotopic parameterization.

The main idea behind $\delta^{18} \mathrm{O}: \delta^{2} \mathrm{H}$ plots is that evaporation should drive evaporating vapour and residual waters along a line that has a slope of $<8$, because of the different transport diffusivities of ${ }^{1} \mathrm{H}_{2}{ }^{18} \mathrm{O}$ and ${ }^{1} \mathrm{H}^{2} \mathrm{H}^{16} \mathrm{O}$ (Gonfiantini 1986). The slope of 8 is an expectation based on experimental diffusivities of the two isotopologues. The slope of the evaporation line $\left(\delta^{18} \mathrm{O}: \delta^{2} \mathrm{H}\right)$ is humidity dependent, and varies from $\sim 3.5$ at $0 \%$ relative humidity to $\sim 8$ at $100 \%$. The evaporates and residual water in the 
evaporating reservoir will lie along this evaporation line to the left and right of the GMWL respectively. In Figures 15-17, the expectation is that $\delta$ evaporation from soil and canopy interception $(\delta E v)$ will fall to the left of the GMWL, since the evaporation should be isotopically depleted, relative to the soilwater and canopy-intercepted water. However, if the total evapotranspiration (plot (b)) is made up of a relatively high proportion of transpiration, then the $\delta$ evaporation ( $\delta E v a p)$ distribution should fall closer to the GMWL, since at monthly timescales, which should approximate a steady state situation, the expectation is that $\delta$ transpiration $(\delta T r)=\delta$ root zone water (see Twining et al., 2006) (weighted appropriately). This is a minimalist interpretation, and the situation is much more complex, even in an ILSS due to root zone isotope gradients driven by soil evaporation (these effects have yet to be properly assessed).

We can deduce that the $\delta$ Evap values of ILSSs D and E appear to be more affected by soil and canopy evaporation than by transpiration. ILSSs A and C show a wide range of behaviours from place to place. For example, for C, in Manaus, $\delta$ Evap is depleted relative to the GMWL while $\mathrm{A}$ is not (Figure 15). In comparison, $\mathrm{A}$ and $\mathrm{C}$ are both depleted in Tumbarumba, but not to the extent of E and D (Figure 17). Again, these behaviours cannot be easily explained without a detailed analysis of the size and residence times of the soil reservoirs which are the source of evaporation and transpiration, and the mixing and selection processes which affect these reservoirs (the general explanation for trends in the isotopic annual budget has been provided in Section 4.3). 
In these $\delta^{18} \mathrm{O}: \delta^{2} \mathrm{H}$ plots, $\delta$ runoff may also be expected to be similar to $\delta$ precipitation because the precipitation that runs off should be unfractionated. This pattern seems to be true for ILSSs A and C, but not for D and E. From the ILSSs D and E, it appears that the rainfall that runs off is only a very small proportion of the monthly precipitation, and it is also much more isotopically depleted than the weighted average monthly rainfall. Isotopic depletion in rainfall is typical of storms of long duration or high intensity, both of which fill the soil reservoir in D and E, and hence runoff would generally occur in the more isotopically depleted parts of a storm. This analysis emphasizes the value of isotopes for examining the selection processes that operate in different ILSSs and how they impact upon the feedbacks from the land surface to the atmosphere.

\subsection{SWI evaluation}

SWIs can be used in two distinct ways to evaluate land-surface parameterizations: (i) direct comparison of the SWI character of water stores and fluxes simulated by ILSSs with isotopic observations and (ii) comparing LSS predictions of the relative proportions of water fluxes with the proportions determined from isotopic characterization of the sources e.g. transpired vs. non-transpired SWIs. (We note that isotopes can only be used to estimate flux partitioning if transpiration occurs at isotopic steady state (see Lai et al. 2005, page 14) which has not yet been proven for Tumbarumba). Here, examples of both methods are given as illustrations of the power of SWIs in improving land-surface coding. The observational example comes from a preliminary interpretation of results from the Tumbarumba campaign in March 2005. Although these data have been substantially revised following recognition of 
operational difficulties on March 7th (Twining et al., 2006), the preliminary $\delta^{2} \mathrm{H}$ values serve to illustrate the methodology.

Figure 18 compares the $\delta^{2} \mathrm{H}$ of the transpired and non-transpired moisture fluxes as predicted by the 5 ILSSs for March 7 of EQY1. The heavy black dashed lines are the diurnally-averaged $\delta^{2} \mathrm{H}$ values for these 2 fluxes deduced from the preliminary FTIR results using the Keeling plot method (see Henderson-Sellers, 2006). The soil evaporation has $\delta^{2} \mathrm{H} \approx-95 \%$ while the transpired flux has $\delta^{2} \mathrm{H} \approx-40 \%$. As Figure 18 illustrates none of the ILSSs predict $\delta^{2} \mathrm{H}$ values as depleted as those deduced from the Keeling method. The ILSS (D) achieving the most depleted $\delta^{2} \mathrm{H}$ values in soil plus canopy evaporation $(E v)$ suffers other drawbacks particularly the lack of any diurnal signal in the transpired $(\operatorname{Tr}) \delta^{2} \mathrm{H}$ combined with quite enhanced values. Interestingly, ILSSs $\mathrm{C}$ and $\mathrm{D}$ exhibit remarkably different $\delta^{2} \mathrm{H}$ characteristics for these two fluxes even though they share a roughly central (i.e. "satisfactory") position in the "PILPS plot" (Figure 9) for Tumbarumba. We have, therefore, shown that the hydrology of at least ILSS D requires further investigation on the basis of the $\delta^{2} \mathrm{H}$ characterisation of transpired and non-transpired evaporative fluxes.

It is possible to take preliminary FTIR data further by using the $\delta^{2} \mathrm{H}$ characteristics to partition transpired and non-transpired fluxes. In the initial analysis for $7 \mathrm{March}$, a roughly 50/50 split was found (N.B. the method is yet to be fully proved). Figure 19 illustrates how this partitioning could be applied to evaluate the gross water fluxes simulated by any LSS. If the 50/50 split was correct for 7 March as was originally believed, the 5 ILSSs in iPILPS could all be said to be generating plausible proportionalities. However, if the 50/50 separation of transpired from non-transpired 
were actually for a spring rather than autumn day, say 28 September, then much greater difficulties are clear for some ILSSs. For example, ILSS D transpires $10 \mathrm{~W} \mathrm{~m}^{-}$ ${ }^{2}$, its canopy evaporation is $15 \mathrm{~W} \mathrm{~m}^{-2}$, while the soil evaporation is $77 \mathrm{~W} \mathrm{~m}^{-2}$ i.e. roughly a 10/90 split. In contrast, ILSS A transpires $25 \mathrm{~W} \mathrm{~m}^{-2}$, has a canopy evaporation of $46 \mathrm{~W} \mathrm{~m}^{-2}$ and a soil evaporation of $29 \mathrm{~W} \mathrm{~m}^{-2}$, giving it about a 25/75 separation. Thus, if the isotopically-derived 50/50 partition were correct for either date, it would allow discrimination in September although adding little diagnostic benefit in March.

\section{Summary and Conclusions}

The iPILPS Phase 1 experiments provide the first intercomparison of isotope-enabled land-surface schemes. Given the importance of isotope modelling in understanding the variability of both modern and palaeo-climates and the interpretation of relevant observations (e.g. Cole et al., 1993; Jouzel et al., 1996), correctly capturing the isotopic feedback between the land surface and the atmosphere is critical for appropriate analysis over a wide range of timescales. iPILPS Phase 1 has already delivered significant benefits to individual land-surface scheme owners and users in the form of improvements arising from the analyses described here.

From the experiments presented here, five main conclusions can be drawn: i) firstly, in ILSSs, the partitioning of available energy and water is a function of the schemes' complexity, as was identified in early PILPS experiments. For example, ILSS B (Bucket hydrology) has a relatively high Qle:Qh ratio, while ILSS E (SVAT) has a 
relatively low Qle:Qh ratio. ii) Secondly, the isotopic equilibrium is independent of the total water and energy budget, that is, an ILSS that is in equilibrium with respect to bulk energy and water is not necessarily in isotopic equilibrium. iii) Thirdly, the isotopologues show complex responses to the hydrological parameterizations of different land-surface schemes (given the same surface properties and forcing data for a particular location). A new methodology for understanding the differences in the isotopic response of different ILSSs, the Isotope Transfer Function (ITF), $\delta_{\text {reservoir }}=$ $\boldsymbol{f}$ (mixing, selection, isotope fractionation), is introduced here. The effect of mixing, selection and isotopic fractionation (especially steady or non-steady state), has been observed in the isotopic responses of each of the ILSSs. iv) Fourthly, a new tool for isotope-enabled model intercomparison has been introduced: the iPILPS plot. The iPILPS plot gives a quick summary of the annual isotope mass balance, just as the PILPS sensible and latent heat plot has been used to summarise annual energy budgets (e.g. Chen et al., 1997). Although there are presently too few isotope-enabled land-surface schemes available to be able to properly investigate the relationships between isotope partitioning and model complexity, this plot has been shown here to reveal aspects of LSS characteristics not seen in gross water and energy analyses. v) Finally, we have established that observational campaigns should measure both $\delta^{18} \mathrm{O}$ and $\delta^{2} \mathrm{H}$ in order to facilitate the comparison between observations and isotopicallyenabled models, with the aim of reducing the range of differences among current ILSSs.

\section{Acknowledgments}

We are very grateful to all the ILSS team members who assisted in the creation of the isotopic schemes and in these experiments. We are also grateful to 3 anonymous 
reviewers who made many substantive suggestions by means of which we have greatly improved this intercomparison.

\section{References}

Aleinov, I. and Schmidt, G., 2006. Water isotopes in the GISS Model land surface scheme. Global and Planetary Change, submitted.

Chen T.H., Henderson-Sellers, A., Milly, P.C.D., Pitman, A.J., Beljaars, A.C.M., Polcher, J., Abramopoulos, F., Boone, A., Chang, S., Chen, F., Dai, Y., Desborough, C.E., Dickinson, R.E., Dumenil, L., Ek, M., Garratt, J.R., Gedney, N., Gusev, Y.M., Kim, J., Koster, R., Kowalczyk, E.A., Laval, K., Lean, J., Lettenmaier, D., Liang, X., Mahfouf, J.-F., Megelkamp, H.-T., Mitchell, K., Nasonova, O.N., Noilhan, J., Robock, A., Rozensweig, C., Schaake, J., Schlosser, A., Schulz, J.P., Shao, Y., Shmakin, A.B., Verseghy, D.L., Wetzel, P., Wood, E.F., Xue, Y., Yang, Z.-L. and Zeng, Q., 1997. Cabauw Experimental results from the project for Intercomparison of Land-surface Parameterization Schemes. J. Climate, 10, 1194-1215

Craig, H. and Gordon, L. I., 1965. Deuterium and oxygen 18 variations in the ocean and marine atmosphere, in Stable Isotopes in Oceanographic Studies and Paleotemperatures. E. Tongiorgi, pp. 9-130, Lab. Geologia Nucleare, Pisa, Italy.

Cole, J.E., Rind, D., Webb, R., Jouzel, J. and Healy, R., 1999. Global controls on interannual variability of precipitation $\delta^{18} \mathrm{O}$ : the relative roles of temperature, precipitation amount, and vapor source region. Journal of Geophysical Research, 104, 14223-14235.

Desborough, C. E., 1999. Surface energy balance complexity in GCM land surface models. Climate Dynamics, 15, 389-403.

Dickinson, R. E., Henderson-Sellers, A., Kennedy, P. J. and Wilson, M. F., 1986. Biosphere-Atmosphere Transfer Scheme (BATS) for the NCAR Community Climate Model, NCAR Technical Note TN-275.

Fischer, M. J., 2006. ICHASM, a flexible land-surface model that incorporates stable water isotopes. Global and Planetary Change, submitted.

Fischer, M. and Sturm, K., 2006. REMOiso Forcing for the IPILPS Phase 1 Experiments and the performance of REMOiso in three domains. Global and Planetary Change, submitted.

Gat, J. R., 1996. Oxygen and hydrogen isotopes in the hydrologic cycle. Annual Review of Earth and Planetary Sciences, 24, 225-262.

Henderson-Sellers, A., 2006. Improving land-surface parameterization schemes using stable water isotopes: introducing the iPILPS initiative. Global and Planetary Change, submitted. 
Henderson-Sellers, A., Irannejad, P., McGuffie, K. and Pitman, A. J., 2003. Predicting land-surface climates - better skill or moving targets? Geophys. Res. Lett., 30 (14), 1777-1780.

Henderson-Sellers, A., Irannejad, P., McGuffie, K., Sharmeen, S., Phillips, T.J., McGuffie, K. and Zhang, H., 2003. Evaluating GEWEX CSES' simulated landsurface water budget components. GEWEX News August 2003, 3-6.

Jouzel, J., Koster, R. D. and Joussame, S., 1996, Climate reconstruction from water isotopes: what do we learn from isotopic models? In P. D. Jones, R. S. Bradley and J. Jouzel (eds), 1996., Climate Variations and Forcing Mechanisms of the Last 2000 Years., pp. 213-242., Springer-Verlag, Berlin.

Kistler, R., Kalnay, E., Collins, W., Saha, S., White, G., Woollen, J., Chelliah, M., Ebisuzaki, W., Kanamitsu, M., Kousky, V., H van den Dool, H., Jenne, R. and Fiorino, M., 2001. The NCEP-NCAR 50-Year Reanalysis: Monthly Means CD-ROM and Documentation. Bull. Amer. Meteor. Soc., 82, 247-268.

Lai, C., Ehleringer, J. R., Bond, B. J. and Tha Paw U, K., 2005. Contributions of evaporation, isotopic non-steady state transpiration and atmospheric mixing on the $\delta^{18} \mathrm{O}$ of water vapour in Pacific Northwest coniferous forests. Plant, Cell and Environment, in press.

Manabe, S., 1969. Climate and ocean circulation: 1, the atmospheric circulation and the hydrology of the Earth's surface. Monthly Weather Review, 97, 739-805.

Pitman, A. J., 2003. The evolution of, and revolution in, land surface schemes designed for climate models. International Journal of Climatology, 23, 479-510.

Pitman, A.J., Henderson-Sellers, A., Desborough, C. E.,Yang, Z-L., Abramopoulos, F., Boone, A., Desborough, C.E., Dickinson, R.E., Gedney, N., Koster, R., Kowalczyk, E., Lettenmaier, D., Liang, X., Mahfouf, J-F., Noilhan, J., Polcher, J., Qu, W., Robock, A., Rosenzweig, C., Schlosser, C., Shmakin, A.B., Smith, J., Suarez, M., Verseghy, D., Wetzel, P., Wood, E. and Xue, Y., Key Results and Implications from Phase 1(c) of the Project for Intercomparison of Land-surface Parameterization Schemes, 1999. Climate Dynamics, 15, 673-684.

Riley, W. J., Still, C. J., Torn, M. S. and Berry, J. A, 2002. A mechanistic model of $\mathrm{H}_{2}{ }^{18} \mathrm{O}$ and $\mathrm{C}^{18} \mathrm{OO}$ fluxes between ecosystems and the atmosphere: Model description and sensitivity analyses. Global Biogeochemical Cycles, 16, doi:10.1029/2002GB001878

Rozenzweig, C. and Abramopolous, F., 1997. Land-surface model development for the GISS GCM. Journal of Climate, 10, 2040-2054.

Sellers, P. J., Mintz, Y., Sud, Y. C. and Dalcher, A., 1986. A Simple Biosphere model $(\mathrm{SiB})$ for use within general circulation models. Journal of the Atmospheric Sciences, 43, 505-531. 
Sturm, K., Langmann, B., Hoffman, G. and Stichler, W., 2005a. Stable water isotopes in precipitation: a regional circulation modelling approach. Hydrological Processes, in press.

Sturm, K., Hoffmann, G. and Langmann, B. Simulation of the stable water isotopes in precipitation over South America: comparing global to regional circulation models, Journal of Climate, submitted.

Takata, K., Emori, S. and Watanabe, T., 2003. Development of the minimal advanced treatments of surface interaction and runoff. Global and Planetary Change, 38, 209222.

Twining, J., Stone, D., Tadros, C., Henderson-Sellers, A. and Williams, A., 2006.

Moisture isotopes in the Biosphere and Atmosphere (MIBA) in Australia: the Tumbarumba Field Campaign. Global and Planetary Change, submitted

Weiler, M., McGlynn, B. L., McGuire, K. J. and McDonnell, J. J., 2003. How does rainfall become run-off? A combined tracer and runoff transfer function approach. Water Resources Research, 39, 1315, doi.1029/2003WR002331.

Yoshimura, K., 2006. Iso-Matsiro, a land surface model that incorporates stable water isotopes, Global and Planetary Change, submitted. 
Table 1: Variables provided from REMOiso as forcing for the ILSSs

\begin{tabular}{|c|c|c|c|}
\hline \multicolumn{4}{|l|}{ MODEL FORCING } \\
\hline Definition & \multicolumn{3}{|l|}{ ALMA } \\
\hline & Name & Units & + Sign $^{\star \star \star}$ \\
\hline large-scale precipitation rate $(\mathrm{H} 216 \mathrm{O})$ & **PRECL16 & $\mathrm{kg} \mathrm{m}^{-2} \mathrm{~s}^{-1}$ & Downward \\
\hline Convective precipitation rate $(\mathrm{H} 216 \mathrm{O})$ & **PRECC16 & $\mathrm{kg} \mathrm{m}^{-2} \mathrm{~s}^{-1}$ & Downward \\
\hline atm bottom level ${ }^{\star \star \star \star}$ temperature & Tair & $\mathrm{K}$ & $N / A$ \\
\hline Downward shortwave rad onto surface & Swdown & $\mathrm{W} \mathrm{m^{-2 }}$ & Downward \\
\hline Downward longwave rad onto surface & Lwdown & $\mathrm{W} \mathrm{m^{-2 }}$ & Downward \\
\hline atm bottom level specific humidity (H216O) & Qair & $\mathrm{kg} \mathrm{kg}^{-1}$ & $N / A$ \\
\hline atm bottom level zonal wind & Wind_E & $\mathrm{m} \mathrm{s}^{-1}$ & Eastward \\
\hline atm bottom level meridional wind & Wind_N & $\mathrm{m} \mathrm{s}^{-1}$ & Northward \\
\hline atm surface pressure & Psurf & $\mathrm{Pa}$ & $N / A$ \\
\hline energy of precipitation & Qrain & $\mathrm{W} \mathrm{m^{-2 }}$ & Downward \\
\hline large-scale Precipitation H218O & **PRECL18 & $\mathrm{kg} \mathrm{m}^{-2} \mathrm{~s}^{-1}$ & Downward \\
\hline large-scale Precipitation HDO & **PRECLD & $\mathrm{kg} \mathrm{m}^{-2} \mathrm{~s}^{-1}$ & Downward \\
\hline Convective Precipitation $\mathrm{H} 218 \mathrm{O}$ & **PRECC18 & $\mathrm{kg} \mathrm{m}^{-2} \mathrm{~s}^{-1}$ & Downward \\
\hline Convective Precipitation HDO & **PRECCD & $\mathrm{kg} \mathrm{m}^{-2} \mathrm{~s}^{-1}$ & Downward \\
\hline specific humidity $\mathrm{H} 218 \mathrm{O}$ & **Qair18 & $\mathrm{kg} \mathrm{kg}^{-1}$ & $N / A$ \\
\hline specific humidity HDO & **QairD & $\mathrm{kg} \mathrm{kg}^{-1}$ & $N / A$ \\
\hline large-scale snow H216O & **SNOWL16 & $\mathrm{kg} \mathrm{m}^{-2} \mathrm{~s}^{-1}$ & Downward \\
\hline large-scale snow H218O & **SNOWL18 & $\mathrm{kg} \mathrm{m}^{-2} \mathrm{~s}^{-1}$ & Downward \\
\hline large-scale snow HDO & **SNOWLD & $\mathrm{kg} \mathrm{m}^{-2} \mathrm{~s}^{-1}$ & Downward \\
\hline Convective snow H216O & **SNOWC16 & $\mathrm{kg} \mathrm{m}^{-2} \mathrm{~s}^{-1}$ & Downward \\
\hline Convective snow $\mathrm{H} 218 \mathrm{O}$ & **SNOWC18 & $\mathrm{kg} \mathrm{m}^{-2} \mathrm{~s}^{-1}$ & Downward \\
\hline Convective snow HDO & **SNOWCD & $\mathrm{kg} \mathrm{m}^{-2} \mathrm{~s}^{-1}$ & Downward \\
\hline
\end{tabular}

* ALMA does not use so many solar radiation categories, NCEP Reanalysis names used instead

** ALMA does not have an isotope convention, new conventions suggested

*** ALMA has two sign conventions: We adopt the first here ('Traditional')

$* * * *$ bottom level $=$ the lowest atmospheric level in REMOiso, set at Sigma level $=0.9922814815$

N.B. D is used in variable names instead of ${ }^{2} \mathrm{H}$ 
Table 2: ILSS variables generated in the iPILPS Phase 1 simulations

\begin{tabular}{|c|c|c|c|}
\hline \multirow{3}{*}{\begin{tabular}{|l|} 
MODEL OUTPUTS \\
Definition \\
\end{tabular}} & IPILPS & & \\
\hline & \multicolumn{3}{|l|}{ ALMA } \\
\hline & Name & Units & + Sign \\
\hline Evapotranspiration amount (total) & Evap & $\mathrm{kg} \mathrm{m}^{-2} \mathrm{~s}^{-1}$ & Upward \\
\hline Root zone $^{1}$ drainage & ${ }^{*} \mathrm{Qrz}$ & $\mathrm{kg} \mathrm{m}^{-2} \mathrm{~s}^{-1}$ & Out of Grid Cell \\
\hline Snow melt & Qsm & $\mathrm{kg} \mathrm{m}^{-2} \mathrm{~s}^{-1}$ & Solid to Liquid \\
\hline Total interception storage on the canopy & Canoplnt & $\mathrm{kg} \mathrm{m}^{-2}$ & $N / A$ \\
\hline Total root-zone soil water & Rootmoist & $\mathrm{kg} \mathrm{m}^{-2}$ & N/A \\
\hline Soil moisture (liquid or frozen) in each of all soil layers ${ }^{2}$ & Soilmoist & $\mathrm{kg} \mathrm{m}^{-2}$ & $N / A$ \\
\hline Snow pack & SWE & $\mathrm{kg} \mathrm{m}^{-2}$ & $N / A$ \\
\hline Effective radiative temperature & RadT & $\mathrm{K}$ & N/A \\
\hline Canopy temperature, if present. & VegT & K & N/A \\
\hline Depth averaged temperature for each of all soil layers & SoilTemp & $\mathrm{K}$ & N/A \\
\hline Depth averaged temperature for the root zone & ${ }^{*} \mathrm{RzT}$ & K & $N / A$ \\
\hline Absorbed solar radiation & Qg & $\mathrm{W} \mathrm{m}^{-2}$ & Downward \\
\hline Net radiation & Xnet & $\mathrm{W} \mathrm{m}^{-2}$ & Downward \\
\hline (Incoming solar radiation) - (outgoing SW radiation) & Swnet & $\mathrm{W} \mathrm{m}^{-2}$ & Downward \\
\hline (Incident LW radiation) - (outgoing LW radiation) & Lwnet & $W \mathrm{~m}^{-2}$ & Downward \\
\hline Latent heat flux & Qle & $W \mathrm{~m}^{-2}$ & Upward \\
\hline Sensible heat flux & Qh & $W \mathrm{~m}^{-2}$ & Upward \\
\hline Surface albedo & Albedo & $\%$ & $N / A$ \\
\hline Canopy transpiration & Tveg & $\mathrm{kg} \mathrm{m}^{-2} \mathrm{~s}^{-1}$ & Upward \\
\hline Canopy evaporation & Ecanop & $\mathrm{kg} \mathrm{m}^{-2} \mathrm{~s}^{-1}$ & Upward \\
\hline Ground evaporation & Esoil & $\mathrm{kg} \mathrm{m}^{-2} \mathrm{~s}^{-1}$ & Upward \\
\hline Soil water (in each of all soil layers) & *H2OSOI & $\mathrm{kg} \mathrm{m}^{-2}$ & N/A \\
\hline $\mathrm{H}_{2} 180$ water (in each of all soil layers) & *H18SOI & $\mathrm{kg} \mathrm{m}^{-2}$ & $N / A$ \\
\hline HDO water (in each of all soil layers) & *HDOSOI & $\mathrm{kg} \mathrm{m}^{-2}$ & $N / A$ \\
\hline H218O Canopy Vapour & *RCANV18 & $\mathrm{mol} \mathrm{mol}^{-1}$ & $N / A$ \\
\hline HDO Canopy Vapour & *RCANVD & $\mathrm{mol} \mathrm{mol}^{-1}$ & $N / A$ \\
\hline H2180 Canopy Transpiration & *QVEGT18 & $\mathrm{kg} \mathrm{m}^{-2} \mathrm{~s}^{-1}$ & Upward \\
\hline HDO Canopy Transpiration & *QVEGTD & $\mathrm{kg} \mathrm{m}^{-2} \mathrm{~s}^{-1}$ & Upward \\
\hline H218O Canopy evaporation & *QVEGE18 & $\mathrm{kg} \mathrm{m}^{-2} \mathrm{~s}^{-1}$ & Upward \\
\hline HDO Canopy evaporation & *QVEGED & $\mathrm{kg} \mathrm{m}^{-2} \mathrm{~s}^{-1}$ & Upward \\
\hline H218O Ground evaporation & *QSOIL18 & $\mathrm{kg} \mathrm{m}^{-2} \mathrm{~s}^{-1}$ & Upward \\
\hline HDO Ground evaporation & ${ }^{*} \mathrm{QSOILD}$ & $\mathrm{kg} \mathrm{m}^{-2} \mathrm{~s}^{-1}$ & Upward \\
\hline Surface Runoff & Qs & $\mathrm{kg} \mathrm{m}^{-2} \mathrm{~s}^{-1}$ & Out of Grid Cell \\
\hline H218O Surface Runoff & *Qs18 & $\mathrm{kg} \mathrm{m}^{-2} \mathrm{~s}^{-1}$ & Out of Grid Cell \\
\hline HDO Surface Runoff & ${ }^{*} \mathrm{QsD}$ & $\mathrm{kg} \mathrm{m}^{-2} \mathrm{~s}^{-1}$ & Out of Grid Cell \\
\hline Subsurface Runoff (in each of all soil layers) & Qsb & $\mathrm{kg} \mathrm{m}^{-2} \mathrm{~s}^{-1}$ & Out of Grid Cell \\
\hline H218O Subsurface Runoff (in each of all soil layers) & ${ }^{*} \mathrm{Qsb} 18$ & $\mathrm{~kg} \mathrm{~m}^{-2} \mathrm{~s}^{-1}$ & Out of Grid Cell \\
\hline HDO Subsurface Runoff (in each of all soil layers) & *QsbD & $\mathrm{kg} \mathrm{m}^{-2} \mathrm{~s}^{-1}$ & Out of Grid Cell \\
\hline
\end{tabular}

* new ALMA variables (N.B. D is used in variable names instead of ${ }^{2} \mathrm{H}$ )

1 'Root zone' in ALMA is the soil layer that its moisture is available for transpiration

2 The number and depth of all soil layers used in the ILSS are required. 
Table 3: (a) Soil and (b) vegetation parameters used in iPILPS Phase 1 numerical experiments for Manaus, Munich and Tumbaramba. The ecotypes and mean annual air temperature of the sites are also included.

(a)

\begin{tabular}{|c|c|c|c|c|c|c|c|c|c|}
\hline & & & \multicolumn{3}{|c|}{ Soil particle size } & \multicolumn{4}{|c|}{ Soil albedos } \\
\hline Location & $\begin{array}{l}\text { Ecotype \& } \\
\text { Climate }\end{array}$ & $\begin{array}{l}\text { Annual } \\
\text { mean air } \\
\text { temp. }(\mathrm{K})\end{array}$ & $\begin{array}{l}\% \\
\text { sand }\end{array}$ & $\begin{array}{l}\% \\
\text { silt }\end{array}$ & $\begin{array}{l}\% \\
\text { clay }\end{array}$ & $\begin{array}{l}\text { Dry } \\
\text { VIS }\end{array}$ & $\begin{array}{l}\text { Dry } \\
\text { NIR }\end{array}$ & $\begin{array}{l}\text { Wet } \\
\text { VIS }\end{array}$ & $\begin{array}{l}\text { Wet } \\
\text { NIR }\end{array}$ \\
\hline Manaus & $\begin{array}{l}\text { Tropical } \\
\text { Rainforest }\end{array}$ & 300 & 43.6 & 19.0 & 37.4 & 0.18 & 0.36 & 0.09 & 0.18 \\
\hline Munich & $\begin{array}{l}\text { Mid-lat. } \\
\text { Deciduous } \\
\text { woodland }\end{array}$ & 281 & 31.2 & 38.8 & 30.0 & 0.18 & 0.36 & 0.09 & 0.18 \\
\hline Tumbarumba & $\begin{array}{l}\text { Eucalypt } \\
\text { Woodland }\end{array}$ & 285 & 48.0 & 28.0 & 24.0 & 0.12 & 0.24 & 0.06 & 0.12 \\
\hline
\end{tabular}

(b)

Manaus
\begin{tabular}{|c|l|l|l|l|l|l|l|l|l|l|l|l|}
\hline & JAN & FEB & MAR & APR & MAY & JUN & JUL & AUG & SEP & OCT & NOV & DEC \\
\hline${ }^{1}$ FVC & 0.90 & 0.90 & 0.90 & 0.90 & 0.90 & 0.90 & 0.90 & 0.90 & 0.90 & 0.90 & 0.90 & 0.90 \\
\hline${ }^{2}$ LAI & 5.01 & 5.01 & 5.01 & 5.01 & 5.01 & 5.01 & 5.01 & 5.01 & 5.01 & 5.01 & 5.01 & 5.01 \\
\hline
\end{tabular}

Munich

\begin{tabular}{|l|l|l|l|l|l|l|l|l|l|l|l|l|}
\hline & JAN & FEB & MAR & APR & MAY & JUN & JUL & AUG & SEP & OCT & NOV & DEC \\
\hline FVC & 0.90 & 0.90 & 0.90 & 0.90 & 0.90 & 0.90 & 0.90 & 0.90 & 0.90 & 0.90 & 0.90 & 0.90 \\
\hline LAI & 5.00 & 5.00 & 5.00 & 5.00 & 5.00 & 5.00 & 5.00 & 5.00 & 5.00 & 5.00 & 5.00 & 5.00 \\
\hline
\end{tabular}

Tumbarumba

\begin{tabular}{|l|l|l|l|l|l|l|l|l|l|l|l|l|}
\hline & JAN & FEB & MAR & APR & MAY & JUN & JUL & AUG & SEP & OCT & NOV & DEC \\
\hline FVC & 0.45 & 0.45 & 0.45 & 0.45 & 0.45 & 0.45 & 0.45 & 0.45 & 0.45 & 0.45 & 0.45 & 0.45 \\
\hline LAI & 1.40 & 1.40 & 1.40 & 1.40 & 1.40 & 1.40 & 1.40 & 1.40 & 1.40 & 1.40 & 1.40 & 1.40 \\
\hline
\end{tabular}

${ }^{1}$ Fractional Vegetation Cover

${ }^{2}$ Leaf Area Index 
Table 4: The minimum, median and maximum values of land-surface variables from 5 ILSSs for the equilibrium year (EQY1) for three locations. The values are derived from the unweighted average value of all months.

\begin{tabular}{|c|c|c|c|c|c|}
\hline Site & Variable & Units & Median & Min & Max \\
\hline \multirow[t]{8}{*}{ TUMBAR } & Xnet & $W \mathrm{~m}^{2}$ & 96 & 87 & 102 \\
\hline & Qh & $\mathrm{W} \mathrm{m}^{2}$ & 15 & 8 & 32 \\
\hline & Qle & $W \mathrm{~m}^{-2}$ & 76 & 54 & 80 \\
\hline & Qg & $W \mathrm{~m}^{2}$ & 0 & 0 & 1 \\
\hline & $\operatorname{Pr}$ & $\mathrm{kg} \mathrm{m}^{-2} \mathrm{mon}^{-1}$ & 100 & 51 & 100 \\
\hline & Evap & $\mathrm{kg} \mathrm{m}^{-2} \mathrm{mon}^{-1}$ & 73 & 56 & 83 \\
\hline & Ro & $\mathrm{kg} \mathrm{m}^{2} \mathrm{mon}^{-1}$ & 19 & 1 & 36 \\
\hline & $\Delta S$ & $\mathrm{~kg} \mathrm{~m}^{2} \mathrm{mon}^{-1}$ & 0 & -7 & 5 \\
\hline \multirow[t]{8}{*}{ MANAUS } & Xnet & $W \mathrm{~m}^{2}$ & 151 & 144 & 156 \\
\hline & Qh & $\mathrm{W} \mathrm{m}^{2}$ & 28 & 0 & 49 \\
\hline & Qle & $\mathrm{W} \mathrm{m} \mathrm{m}^{2}$ & 118 & 94 & 156 \\
\hline & Qg & $W \mathrm{~m}^{2}$ & 0 & -1 & 1 \\
\hline & $\mathrm{Pr}$ & $\mathrm{kg} \mathrm{m}^{2} \mathrm{mon}^{-1}$ & 264 & 137 & 264 \\
\hline & Evap & $\mathrm{kg} \mathrm{m}^{2} \mathrm{mon}^{-1}$ & 121 & 97 & 142 \\
\hline & Ro & $\mathrm{kg} \mathrm{m}^{-2} \mathrm{mon}^{-1}$ & 96 & 12 & 176 \\
\hline & $\Delta S$ & $\mathrm{~kg} \mathrm{~m}^{-2} \mathrm{mon}^{-1}$ & 0 & -2 & 15 \\
\hline \multirow[t]{8}{*}{ MUNICH } & Xnet & $W \mathrm{~m}^{-2}$ & 58 & 40 & 66 \\
\hline & Qh & $W \mathrm{~m}^{2}$ & 6 & -12 & 31 \\
\hline & Qle & $W \mathrm{~m}^{2}$ & 43 & 22 & 66 \\
\hline & Qg & $\mathrm{W} \mathrm{m}^{2}$ & 2 & 0 & 5 \\
\hline & $\mathrm{Pr}$ & $\mathrm{kg} \mathrm{m}^{2} \mathrm{mon}^{-1}$ & 93 & 26 & 93 \\
\hline & Evap & $\mathrm{kg} \mathrm{m}^{2} \mathrm{mon}^{-1}$ & 42 & 23 & 69 \\
\hline & Ro & $\mathrm{kg} \mathrm{m}^{2} \mathrm{mon}^{-1}$ & 31 & 2 & 63 \\
\hline & $\Delta S$ & $\mathrm{~kg} \mathrm{~m}^{-2} \mathrm{mon}^{-1}$ & 0 & -3 & 3 \\
\hline
\end{tabular}




\section{Figure Captions}

Figure 1: Components of the monthly surface energy budget. (a,f,k) Xnet = net radiative flux, $(\mathrm{b}, \mathrm{g}, \mathrm{l}) \mathrm{Qh}=$ sensible heat flux, $(\mathrm{c}, \mathrm{h}, \mathrm{m}) \mathrm{Qle}=$ latent heat flux, $(\mathrm{d}, \mathrm{i}, \mathrm{n}) \mathrm{Qg}$ $=$ heat flux into ground, $(\mathrm{e}, \mathrm{j}, \mathrm{o})$ energy imbalance (or error $=X n e t-Q h-Q l e-Q g)$ all in $\mathrm{W} \mathrm{m}^{-2}$ for the final year of the equilibration simulation, EQY1, for Tumbarumba, Manaus, and Munich. ILSSs are designated by letter and line type

Figure 2: Components of the monthly water budget (a,f,k) $\mathrm{Pr}=$ total precipitation, (b,g,l) Evap = total evapotranspiration, $(\mathrm{c}, \mathrm{h}, \mathrm{m}) \mathrm{Ro}=$ total runoff, $(\mathrm{d}, \mathrm{i}, \mathrm{n}) \Delta S=$ total change in stored water (canopy, soil, snow), (e) water imbalance (or error $=\operatorname{Pr}-$ Evap - Ro - $\Delta S$ ) all in $\mathrm{kg} \mathrm{m}^{-2} \mathrm{mon}^{-1}$ for the final year of the equilibration simulation, EQY1, for Tumbarumba, Munich and Manaus. ILSSs are designated by letter and line type. Note that models A-D are forced with the same precipitation data.

Figure 3: Components of the diurnal surface energy budget for January (left) and July (right) created by averaging all 30 days in each month. (a,e) Xnet = net radiative flux, $(\mathrm{b}, \mathrm{f}) \mathrm{Qh}=$ sensible heat flux, $(\mathrm{c}, \mathrm{g})$ Qle = latent heat flux, $(\mathrm{d}, \mathrm{h}) \mathrm{Qg}=$ heat flux into ground, all in $\mathrm{W} \mathrm{m}^{-2}$ for the final year of the equilibration simulation, EQY1, for Manaus. ILSSs are designated by letter and line type.

Figure 4: As for Figure 3, but for Munich

Figure 5: As for Figure 3, but for Tumbarumba

Figure 6: Components of the diurnal water budget for January (left) and July (right) created by averaging all 30 days in each month. (a,e) $\operatorname{Pr}=$ precipitation, (b,f) Ev = (soil+canopy) evaporation, (c,g) $\operatorname{Tr}=$ transpiration, $(\mathrm{d}, \mathrm{h}) \mathrm{Ro}=$ total

(surface+subsurface) runoff, all in $\mathrm{kg} \mathrm{m}^{-2}$ for the final year of the equilibration simulation, EQY1, for Manaus. ILSSs are designated by letter and line type.

Figure 7: As for Figure 6, but for Munich

Figure 8: As for Figure 6, but for Tumbarumba

Figure 9: Components of the annual mean surface (a) energy budget and (b) water budget. The values are scaled according to Equations 5 and 6. ILSSs are designated by letter. Locations are designated by symbol and line type (Manaus = square, dashed, Munich = diamond, dotted, Tumbarumba = circle, solid line). ILSS B is excluded from Panel (b) because of the unexplained errors in its hydrology files.

Figure 10: Components of the monthly water isotope budget (here all $\delta$ s refer to $\left.\delta^{18} \mathrm{O}\right) .(\mathrm{a}, \mathrm{f}, \mathrm{k}) \delta P r=$ isotope ratio of total precipitation, $(\mathrm{b}, \mathrm{g}, \mathrm{l}) \delta E v a p=$ isotope ratio of total evapotranspiration, $(\mathrm{c}, \mathrm{h}, \mathrm{m}) \delta R o=$ isotope ratio of total runoff, $(\mathrm{d}, \mathrm{i}, \mathrm{n}) \Delta \delta S=$ total change in isotope ratio in stored water (canopy, soil, snow), (e) water isotope imbalance $($ or error $=\delta P r-(E v a p * \delta E v a p+R o * \delta R o+\Delta S * \Delta \delta S) / \operatorname{Pr})$ all relative to VSMOW for the final year of the equilibration simulation, EQY1, for Tumbarumba, Manaus and Munich. ILSSs are designated by letter and line type. 
Figure 11: Components of the diurnal water isotope budget (here all $\delta$ s refer to $\delta^{18} \mathrm{O}$ ). (a,e) $\delta P r=$ isotope ratio of precipitation, $(\mathrm{b}, \mathrm{f}) \delta E v=$ isotope ratio of evaporation (soil+canopy), $(\mathrm{c}, \mathrm{g}) \delta \operatorname{Tr}=$ isotope ratio of transpiration, $(\mathrm{d}, \mathrm{h}) \delta R o=$ isotope ratio of surface+subsurface runoff, all relative to VSMOW for the final year of the equilibration simulation, EQY1, for Manaus. ILSSs are designated by letter and line type.

Figure 12: As for Figure 11, but for Munich

Figure 13: As for Figure 11, but for Tumbarumba

Figure 14: Components of the annual mean water isotope budget (here all $\delta$ s refer to $\delta^{18} \mathrm{O}$ ) relative to isoflux (a) and mass (b). ILSSs are designated by letter. Locations are designated by symbols and line type (Manaus = square, dashed, Munich = diamond, dotted, Tumbarumba $=$ circle, solid line). ILSS B is not plotted because of the unexplained errors in its hydrology files.

Figure 15: Components of the twelve monthly water isotope budget, shown as a $\delta^{18} \mathrm{O}: \delta^{2} \mathrm{H}$ plot (a) $\delta P r=$ isotope ratio of total precipitation, (b) $\delta E v a p=$ isotope ratio of total evapotranspiration, (c) $\delta R o=$ isotope ratio of total runoff, (d) $\Delta \delta S=$ isotope ratio of total change in stored water (canopy, soil, snow), all relative to VSMOW for the final year of the equilibration simulation, EQY1, for Manaus. ILSSs are designated by letter and line type. The GMWL line is the dashed diagonal.

Figure 16: As for Figure 15, but for Munich

Figure 17: As for Figure 15, but for Tumbarumba

Figure 18: Diurnal cycle of $\delta^{2} \mathrm{H}$ in (a) non-transpired moisture (i.e. soil and canopy evaporation) and (b) transpiration as simulated by the 5 ILSSs (A-E) at Tumbarumba, taken from the EQY1 for 7 March. The observations are single values ( diurnal means) of transpired and non-transpired flux derived from the FTIR measurements using the Keeling method.

Figure 19: Annual cycle of latent flux components (a) transpiration, (b) canopyintercepted water evaporation and (c) soil evaporation as simulated by the 5 ILSSs for EQY1. The two vertical lines show the March 7 and September 28 dates. The March 7 date corresponds to one day during the Tumbarumba field campaign (Twining et al. 2006). The September 28 day corresponds to a possible sampling day (see text). 

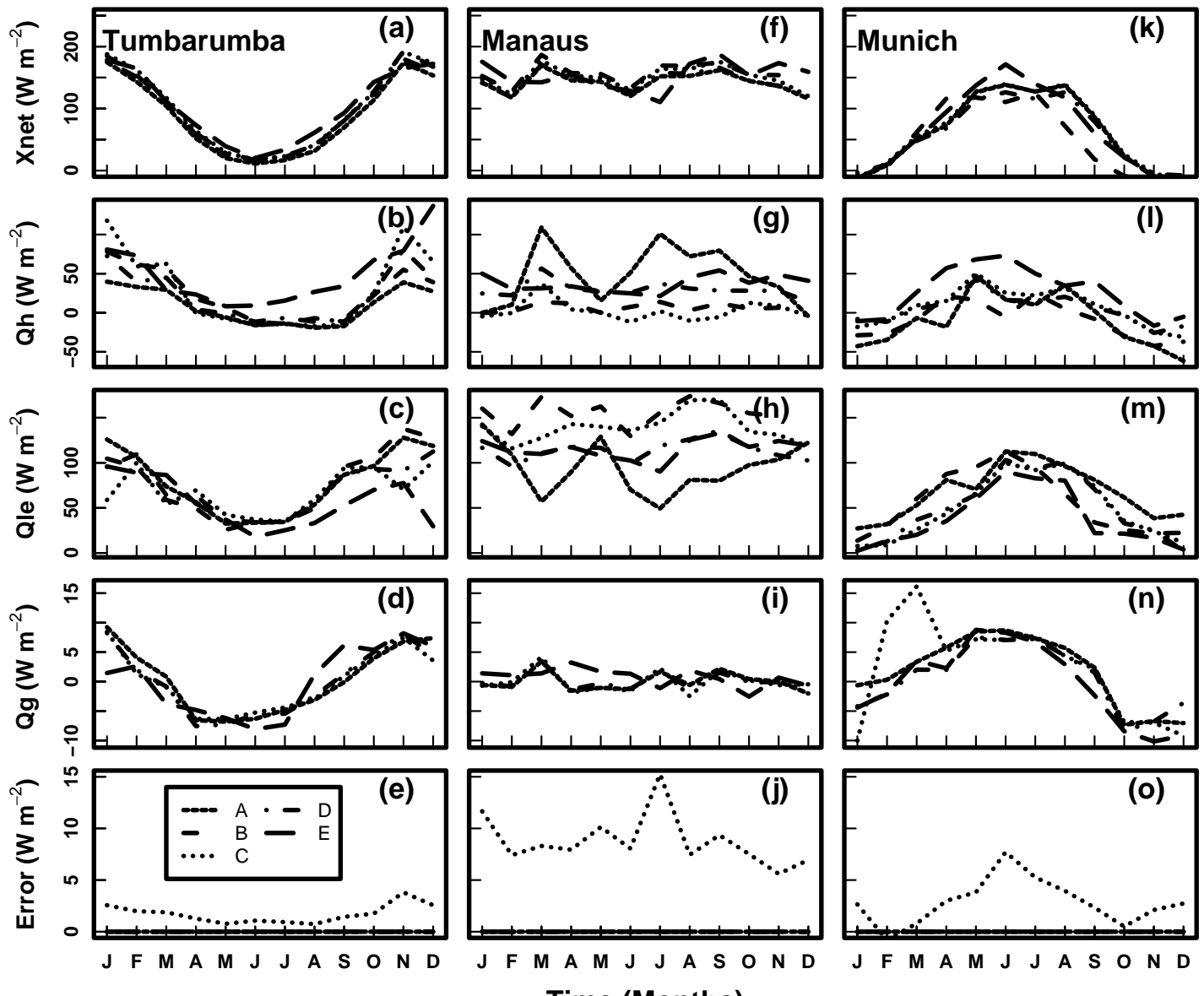

Time (Months)

Figure 1 


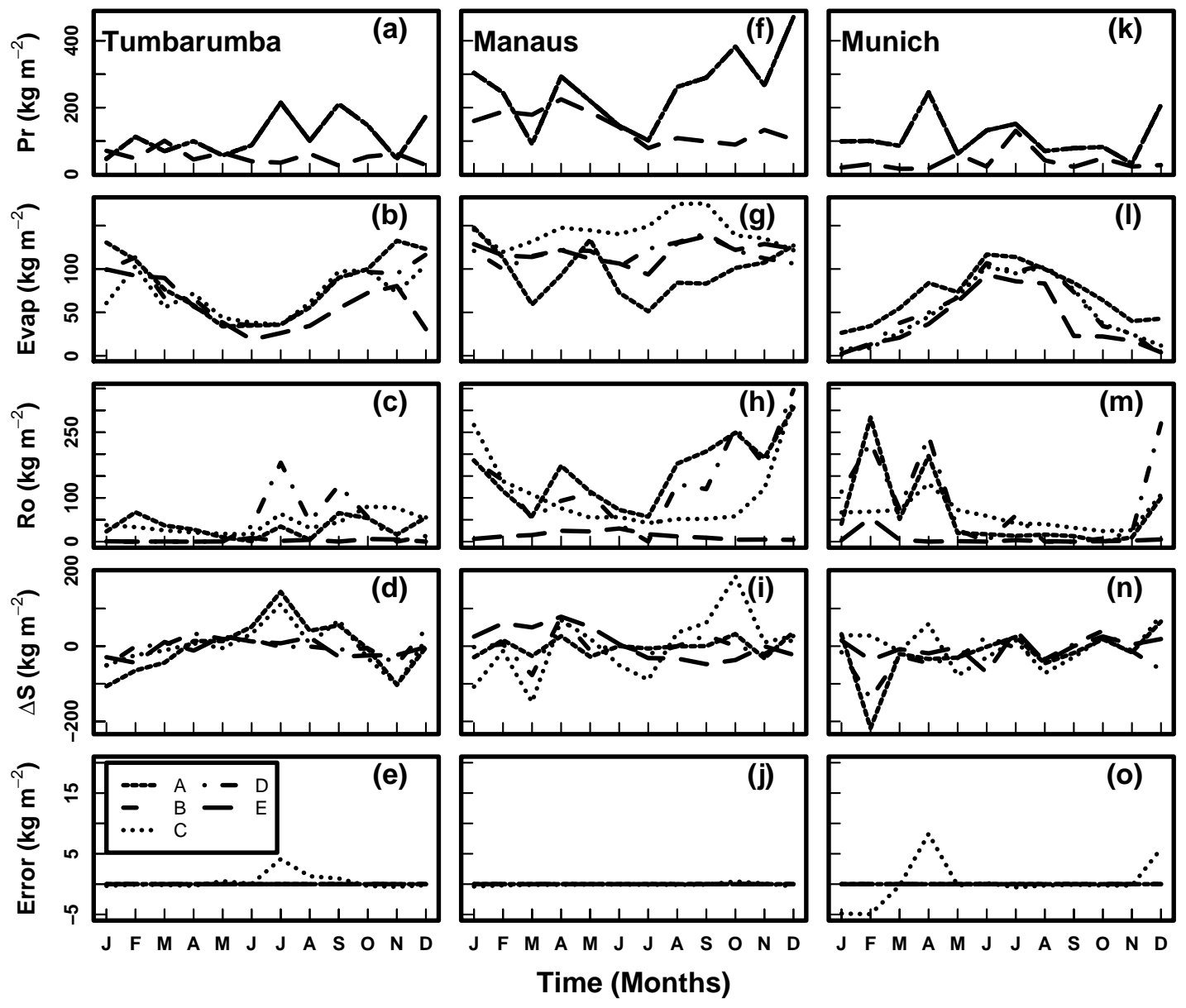

Figure 2 

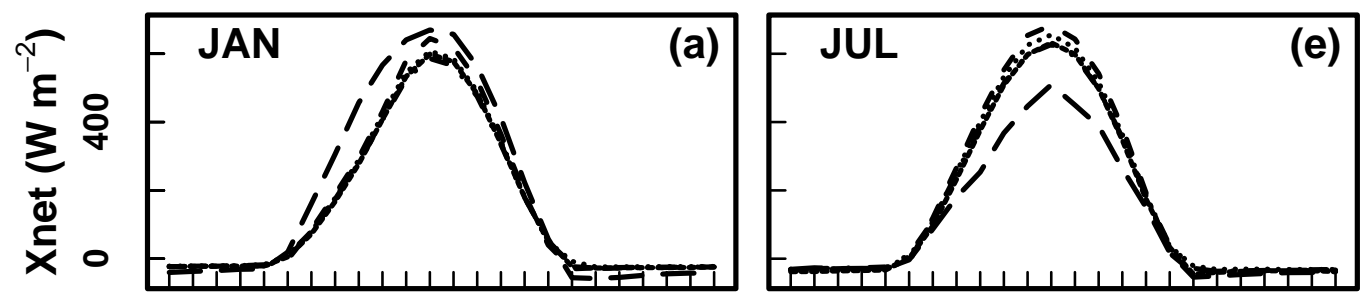

ช

(b)
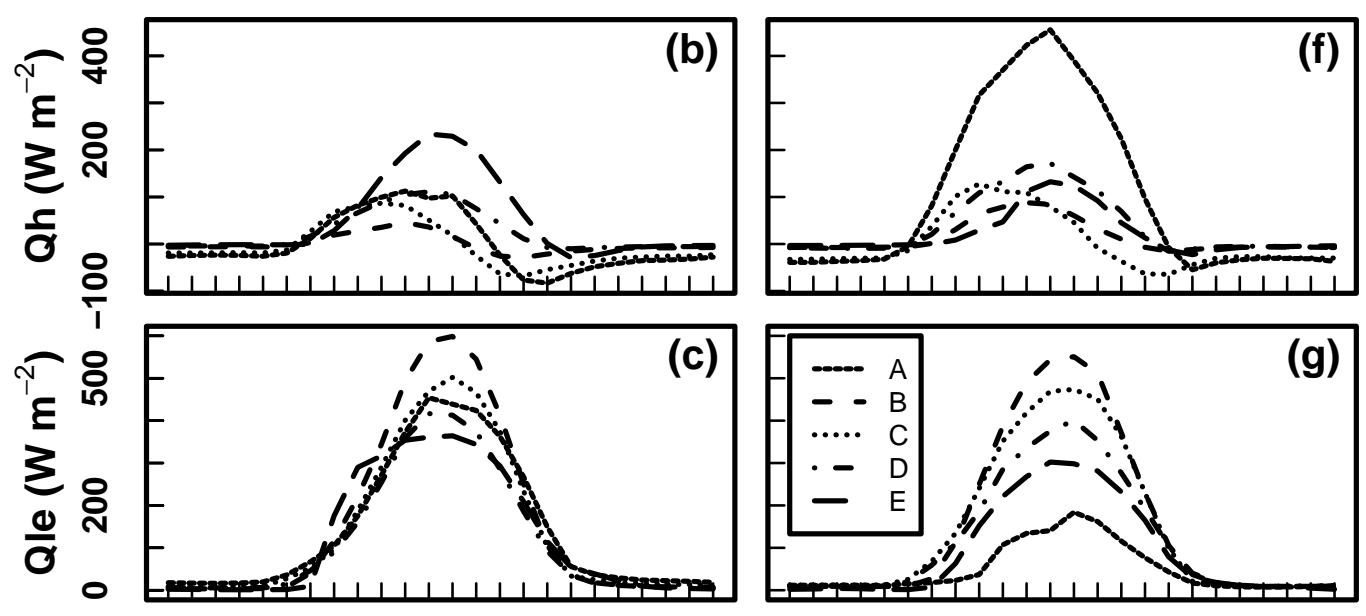

है

(d)

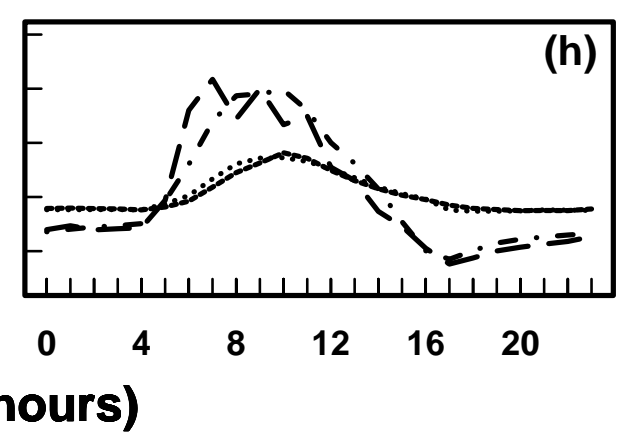

Figure 3 

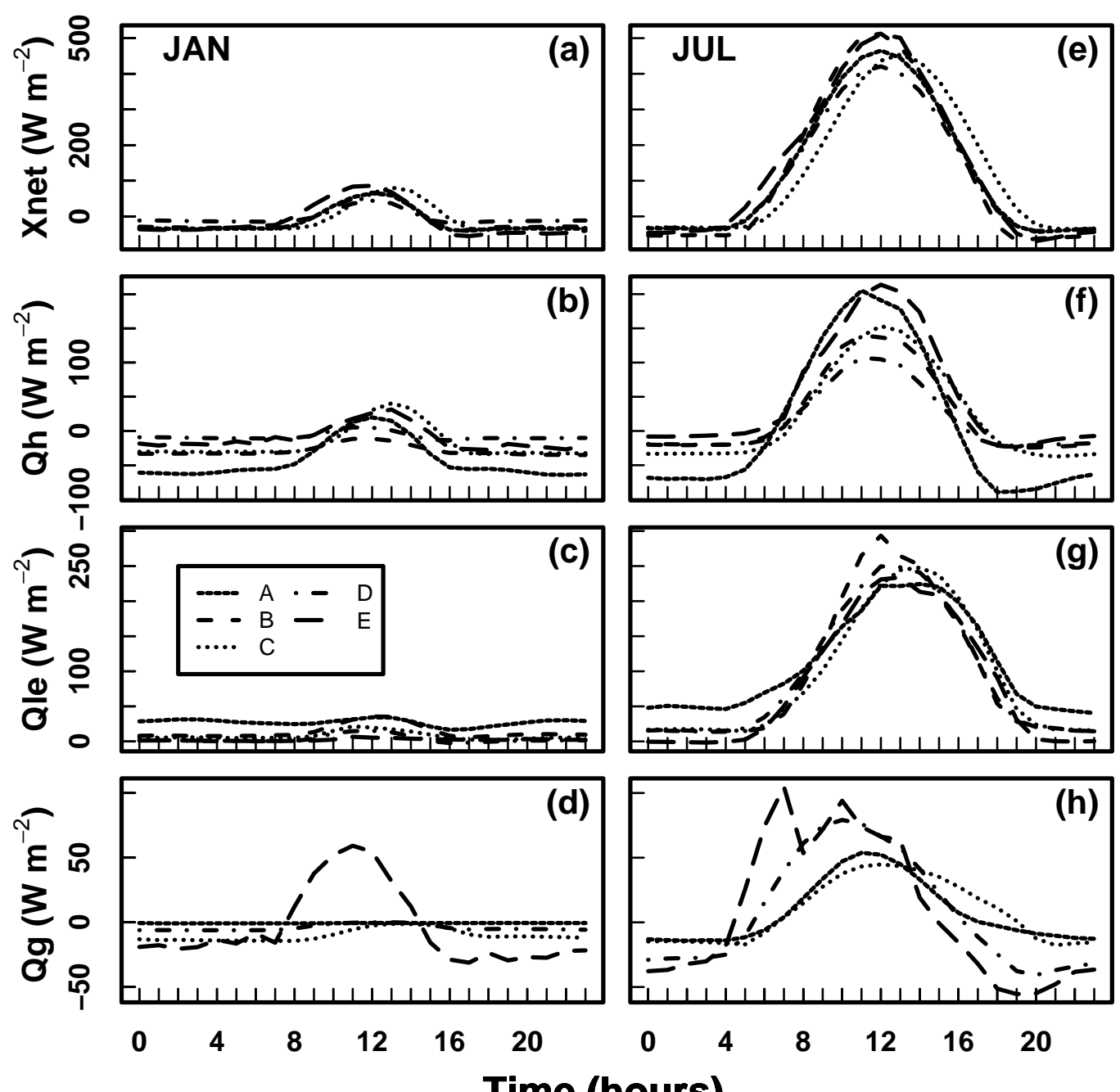

Figure 4

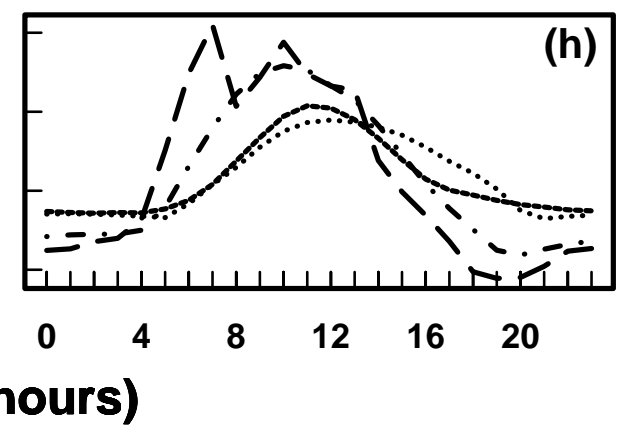



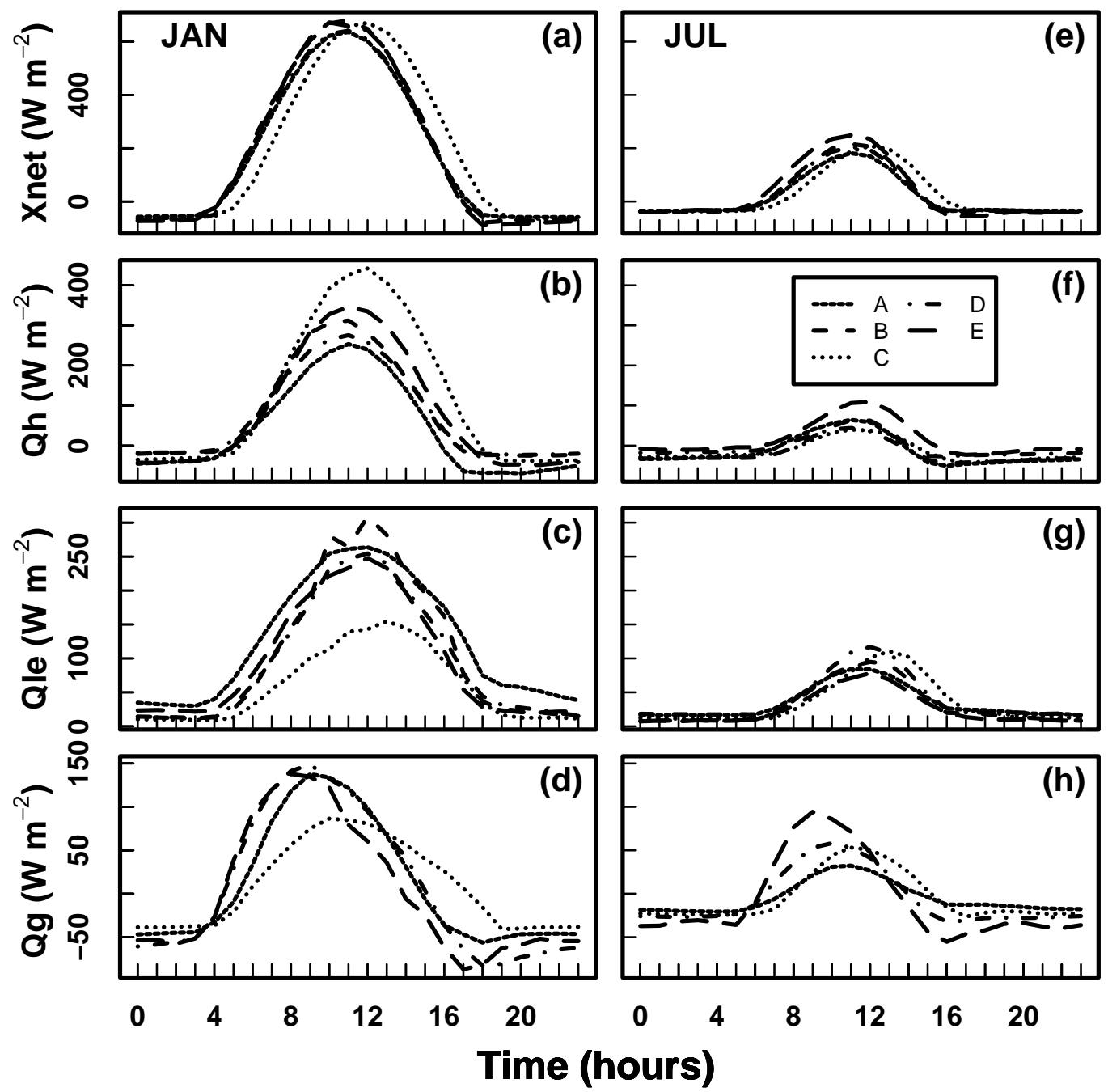

Figure 5 


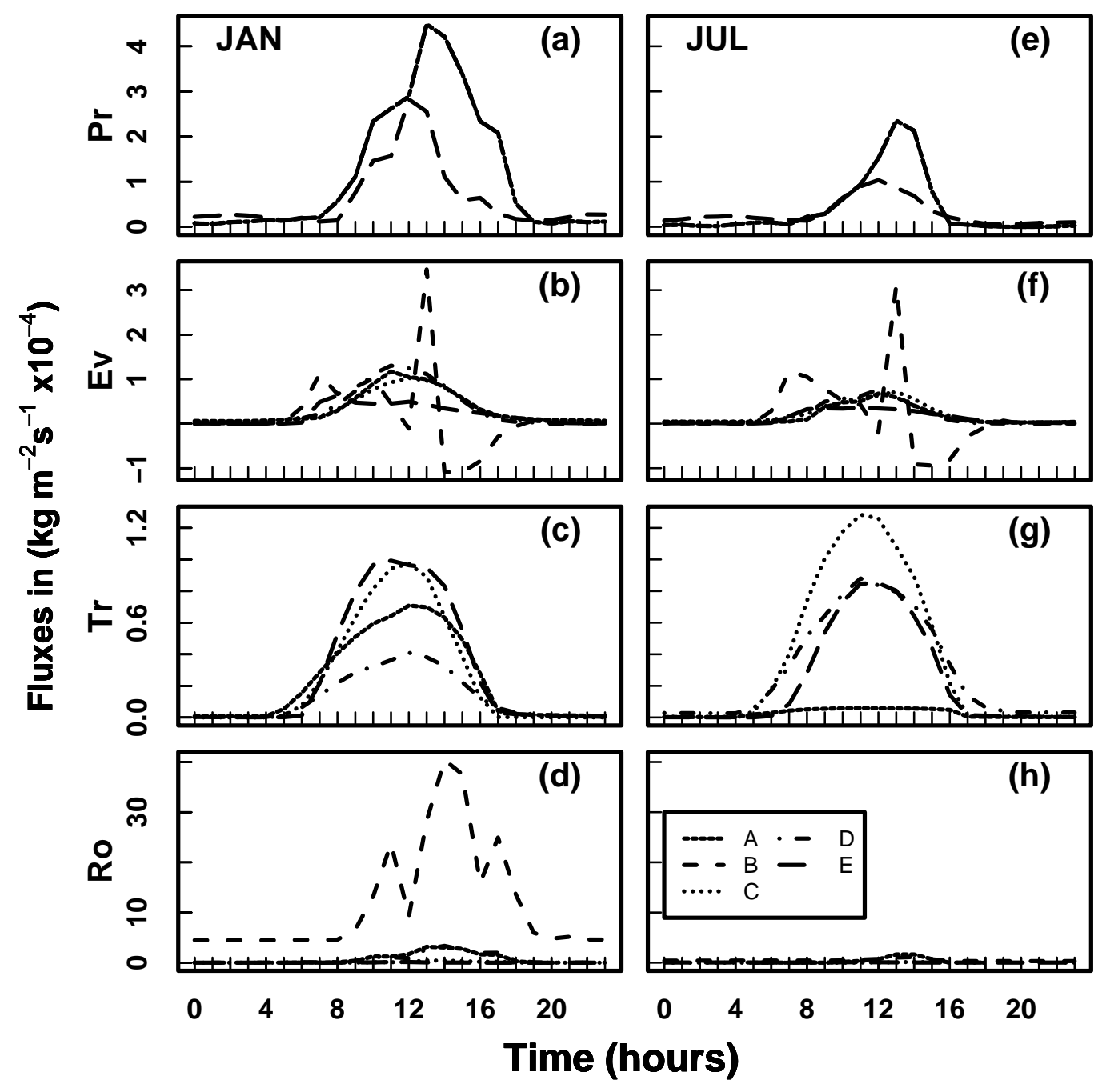

Figure 6 


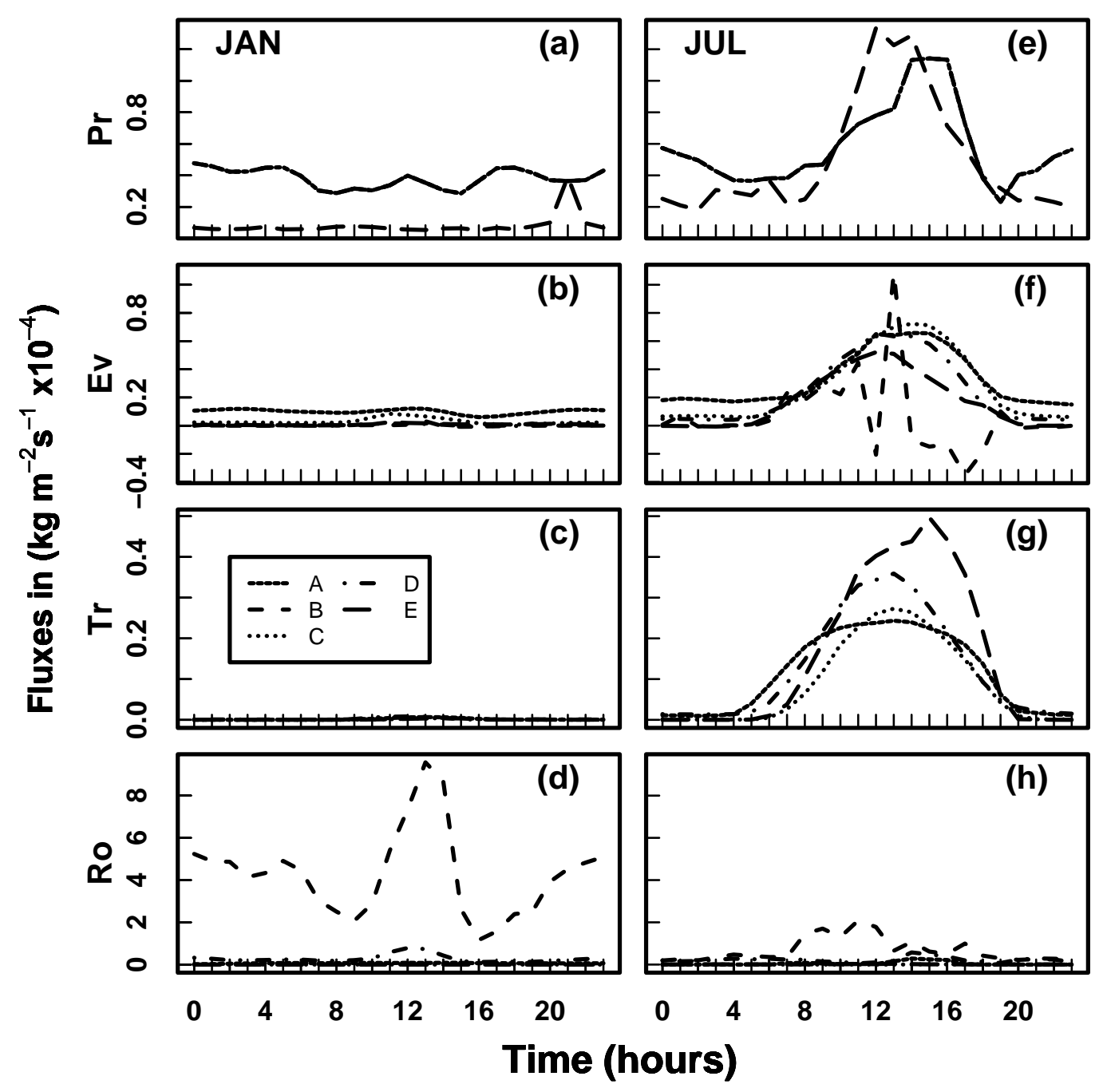

Figure 7 


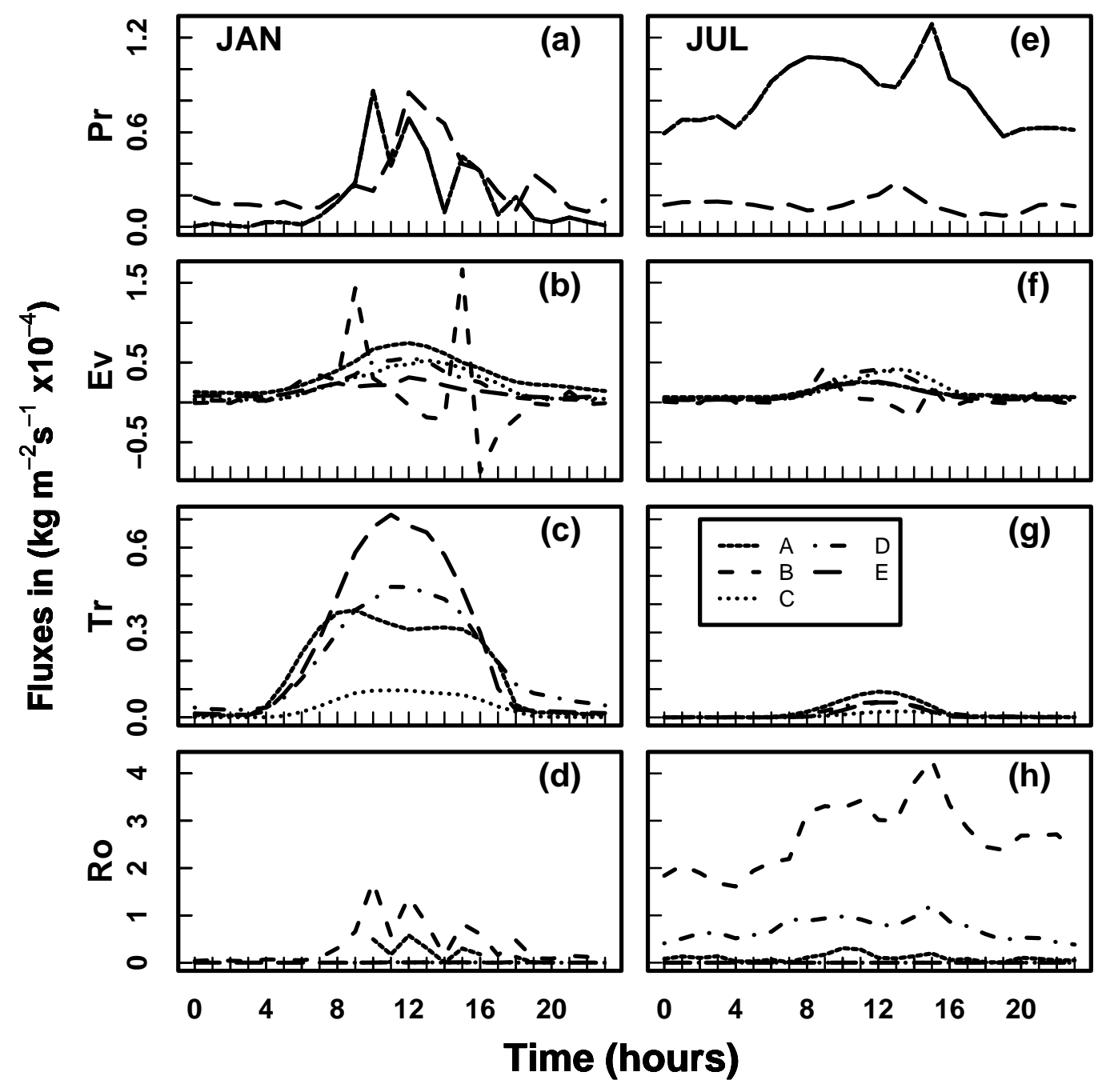

Figure 8 

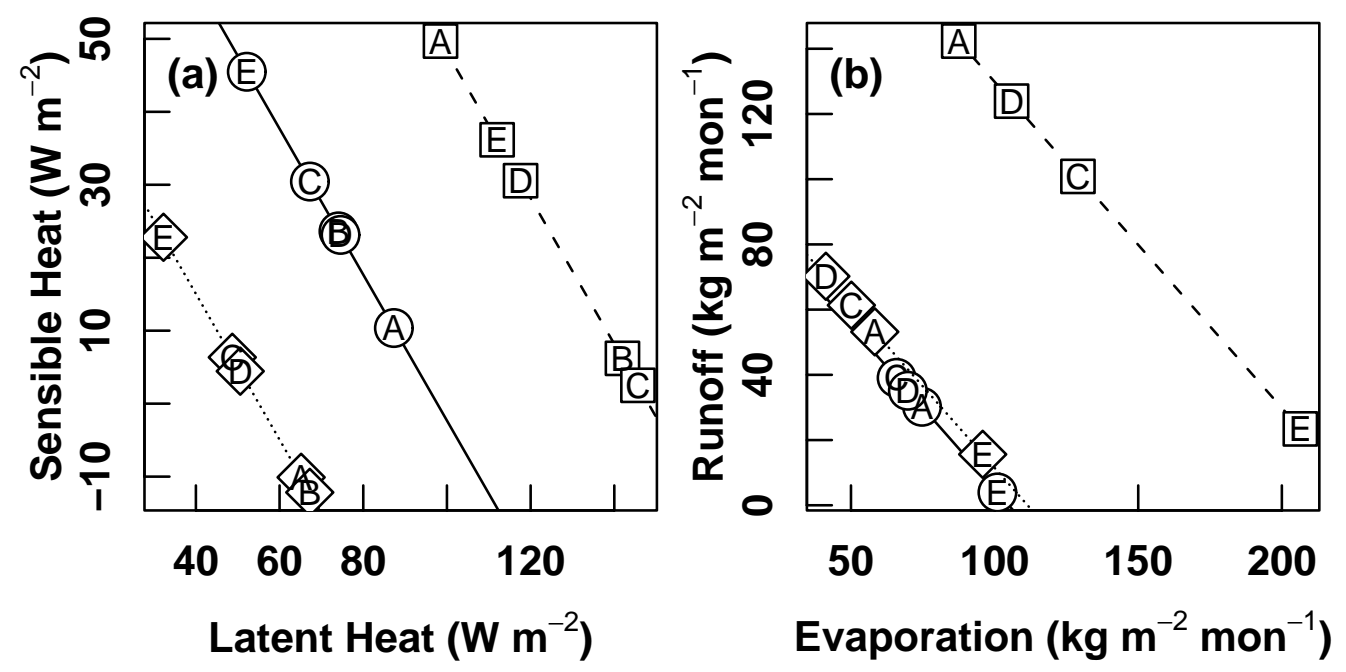

Figure 9 


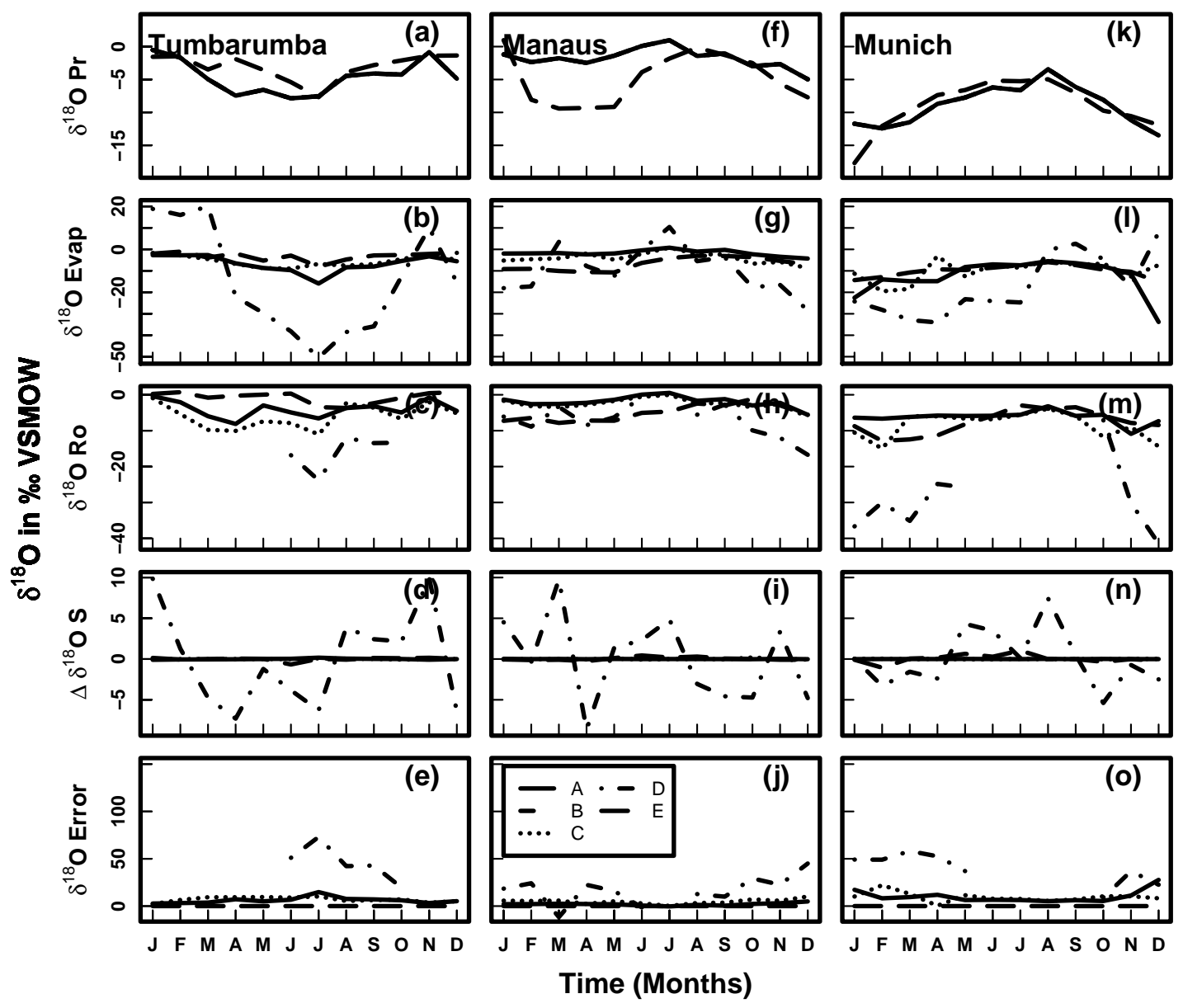

Figure 10 

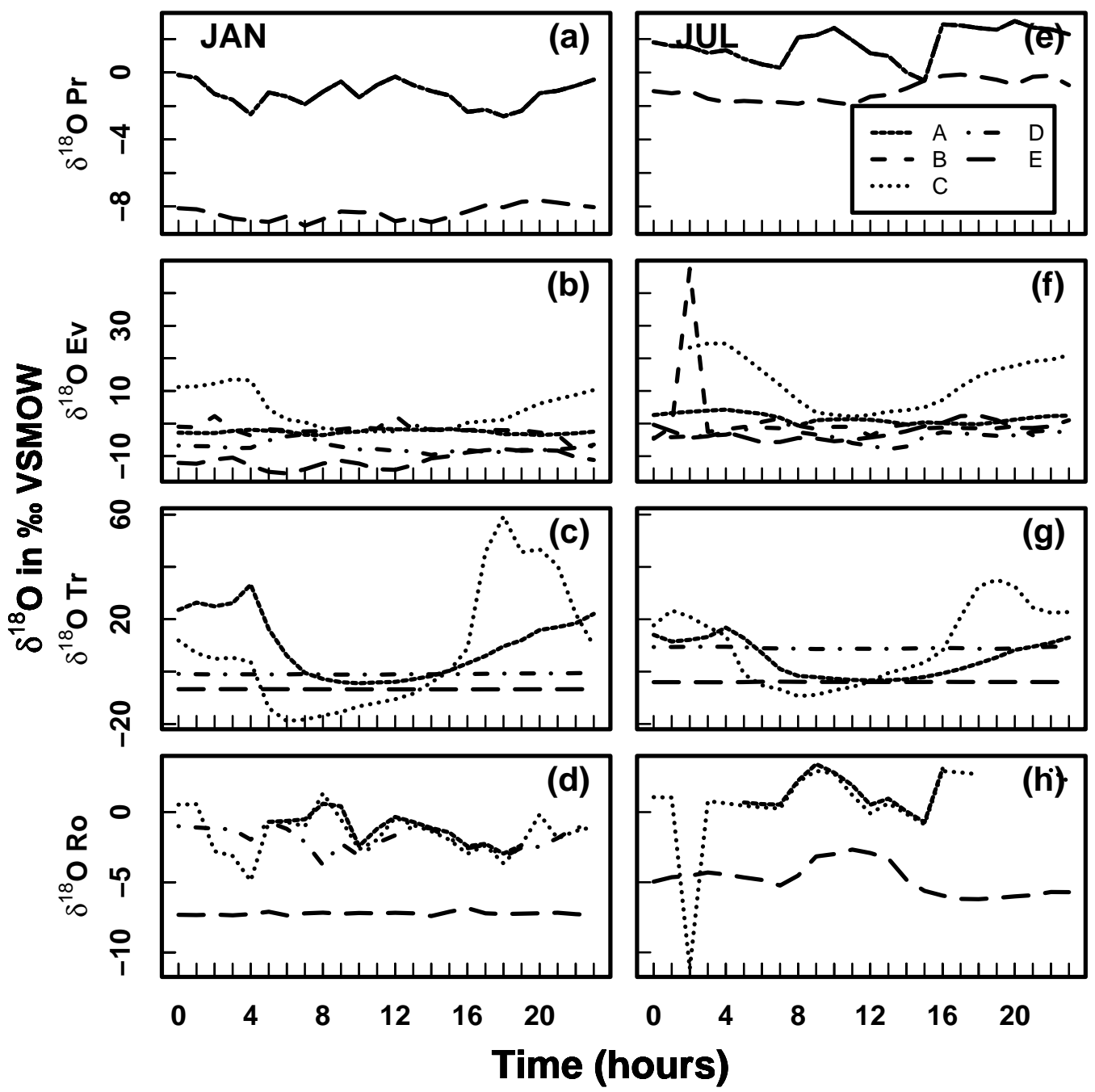

Figure 11 

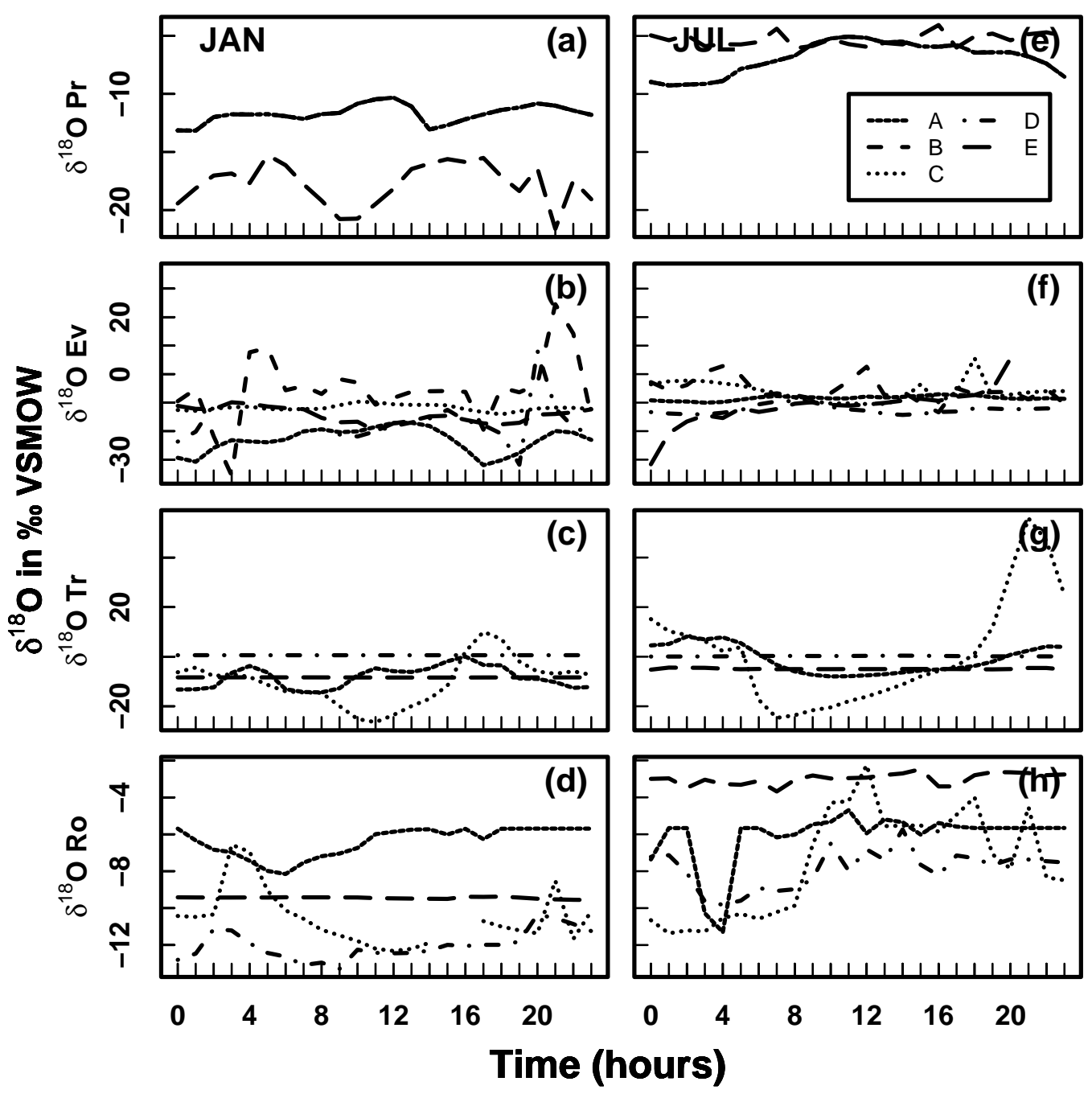

Figure 12 


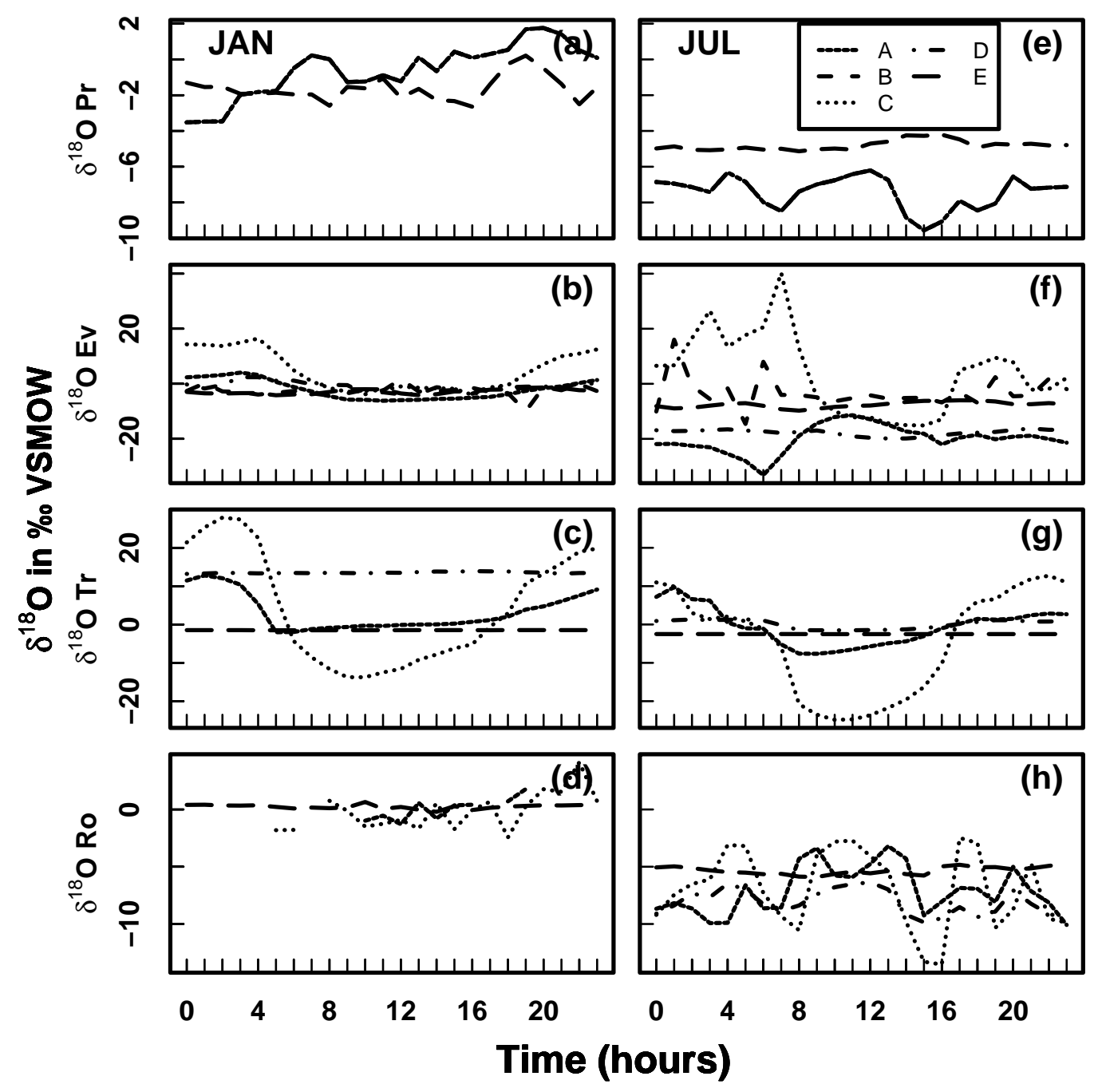

Figure 13 


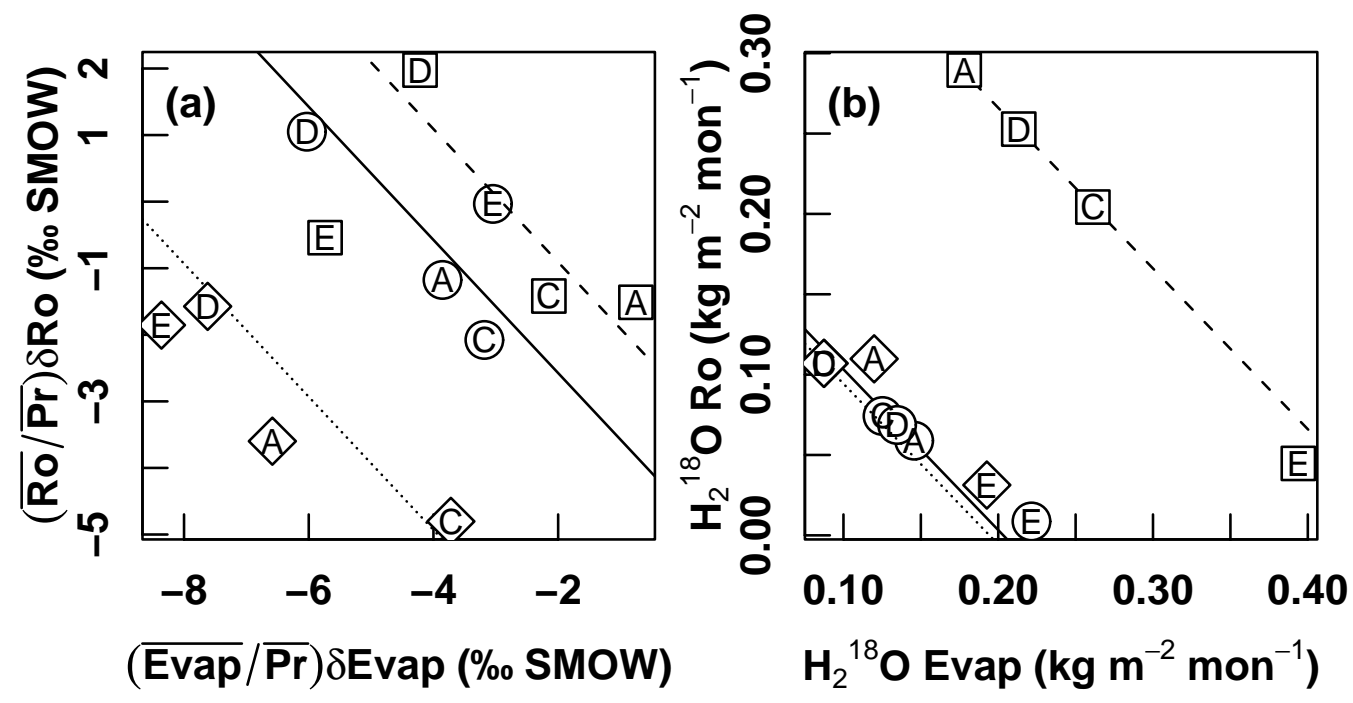

Figure 14 

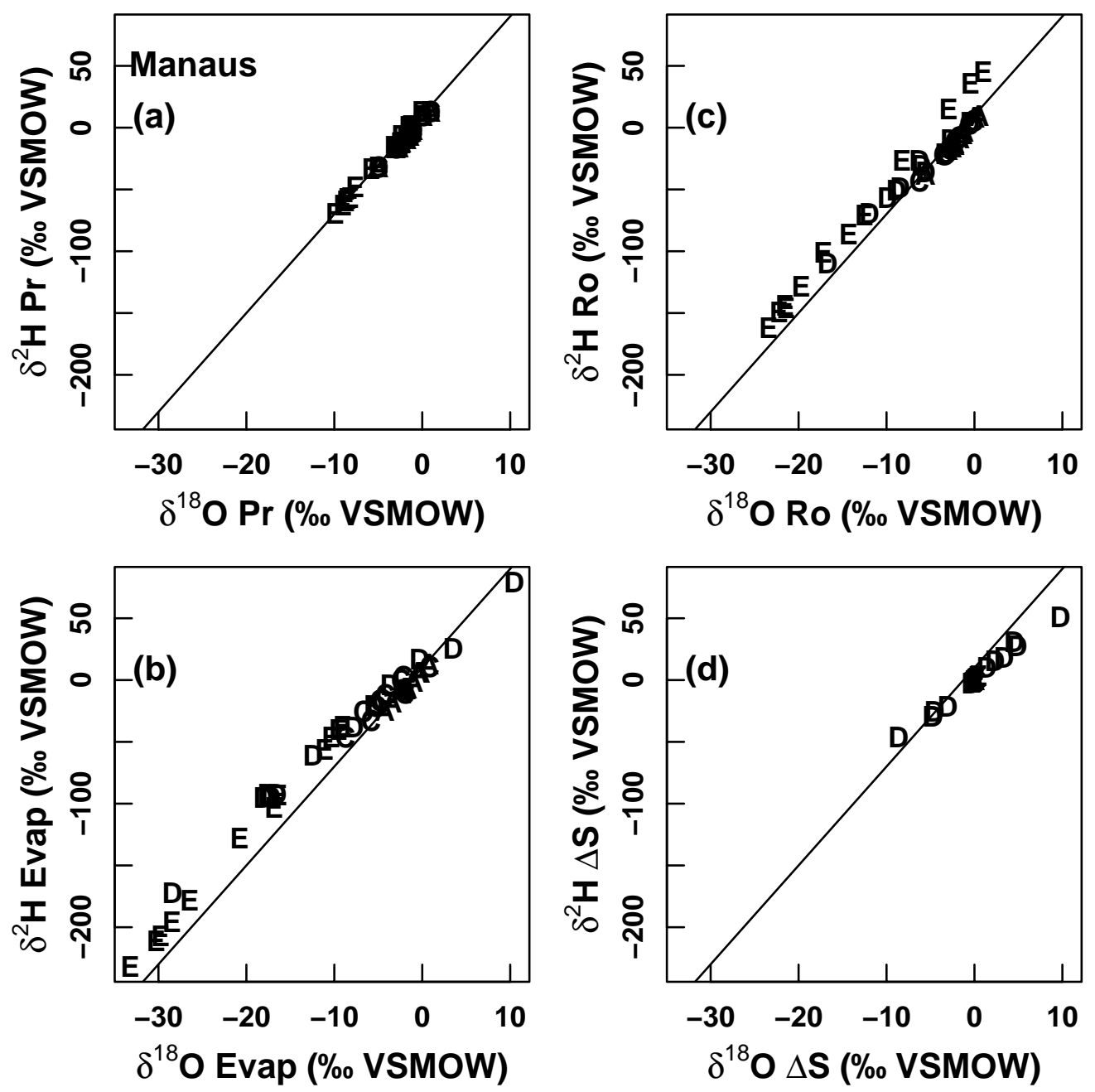

Figure 15 

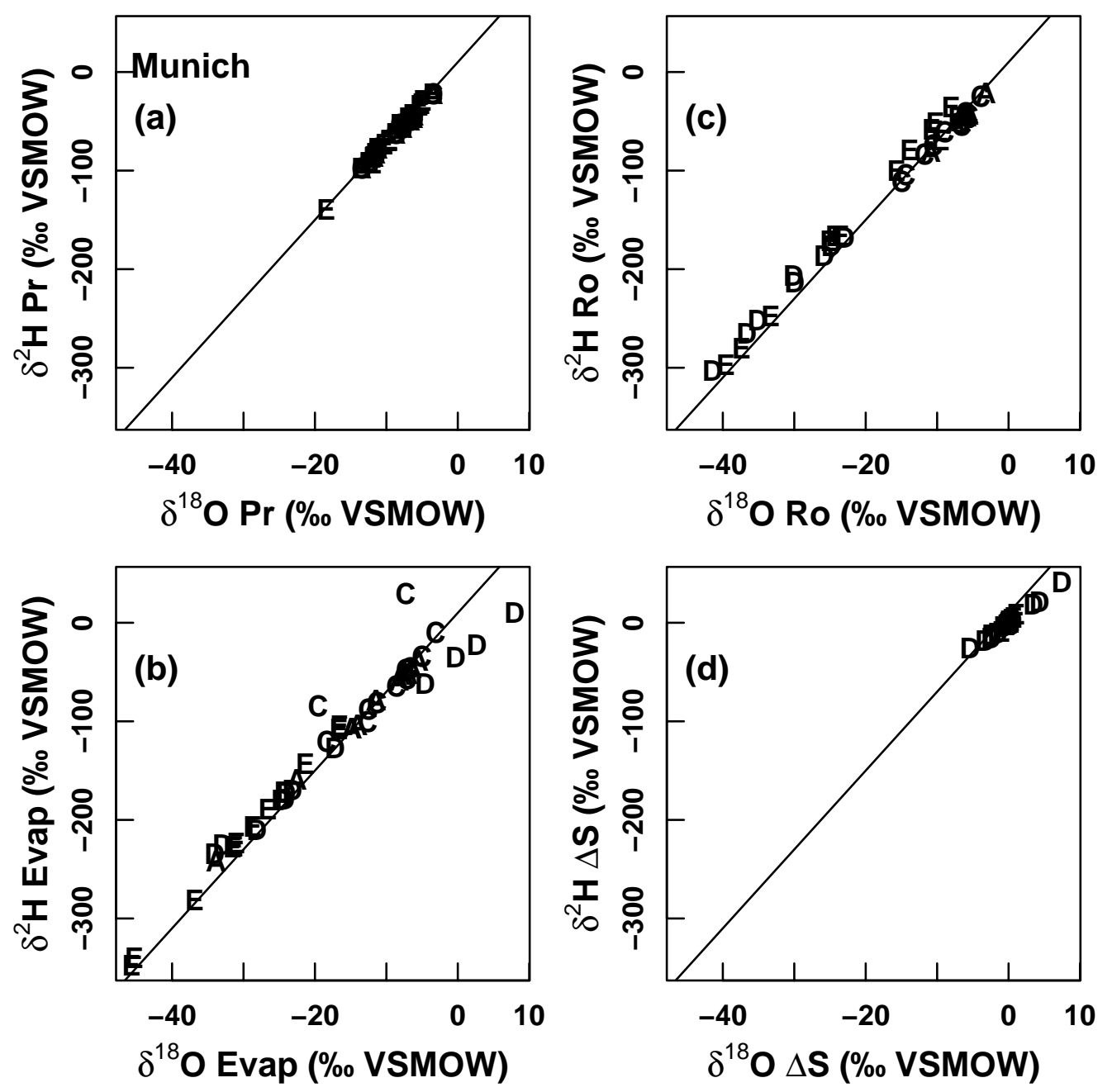

Figure 16 

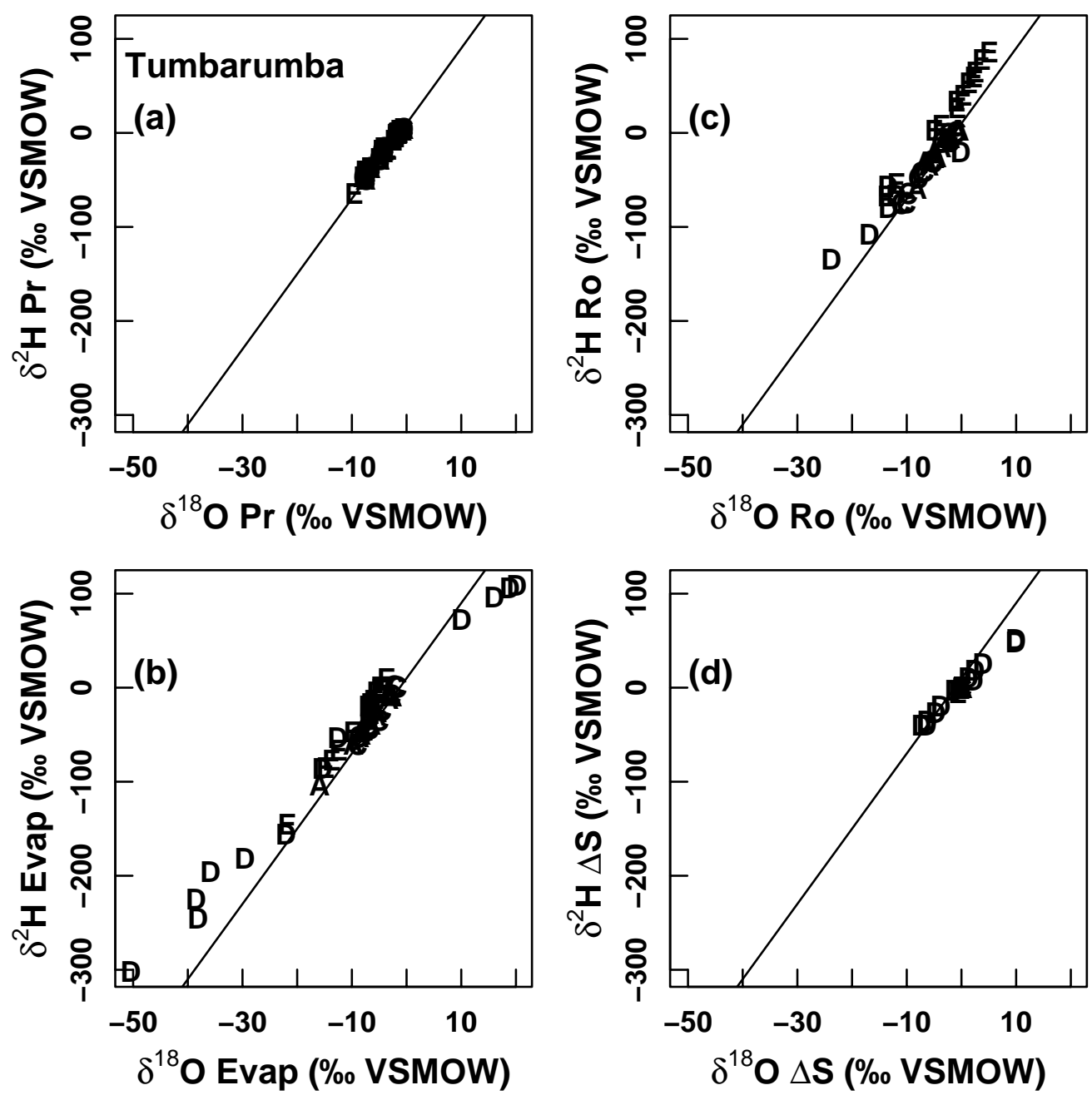

Figure 17 


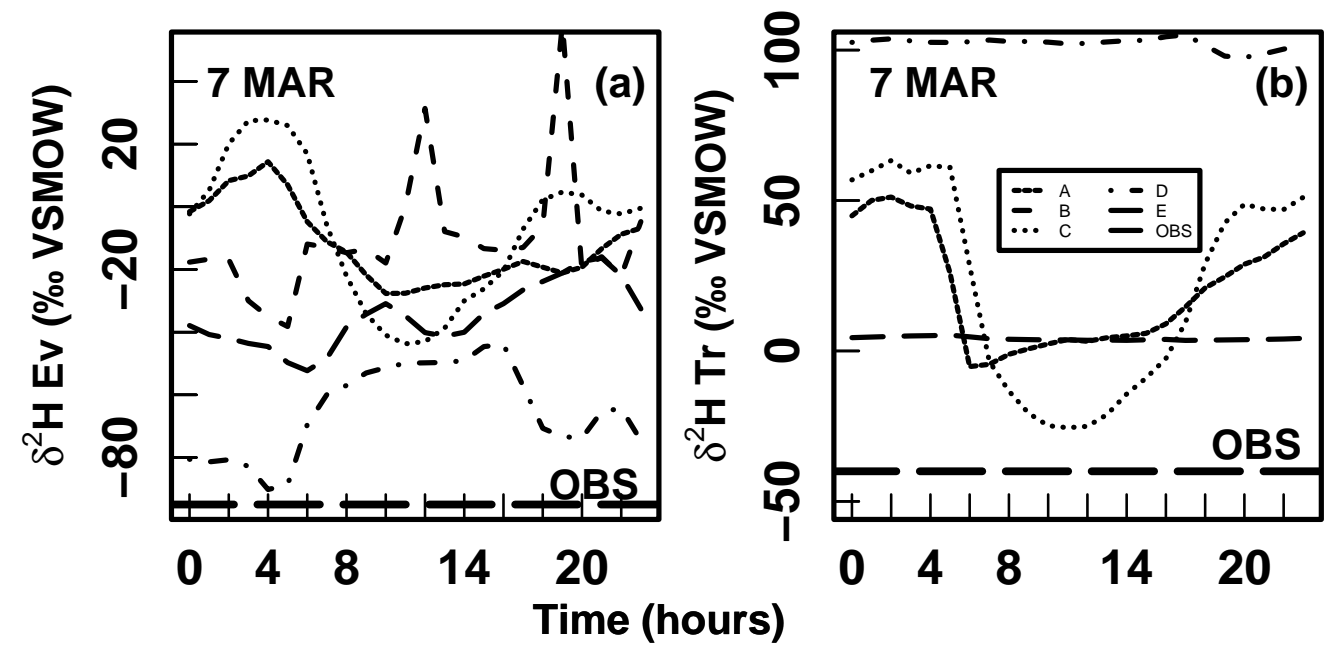

Figure 18 

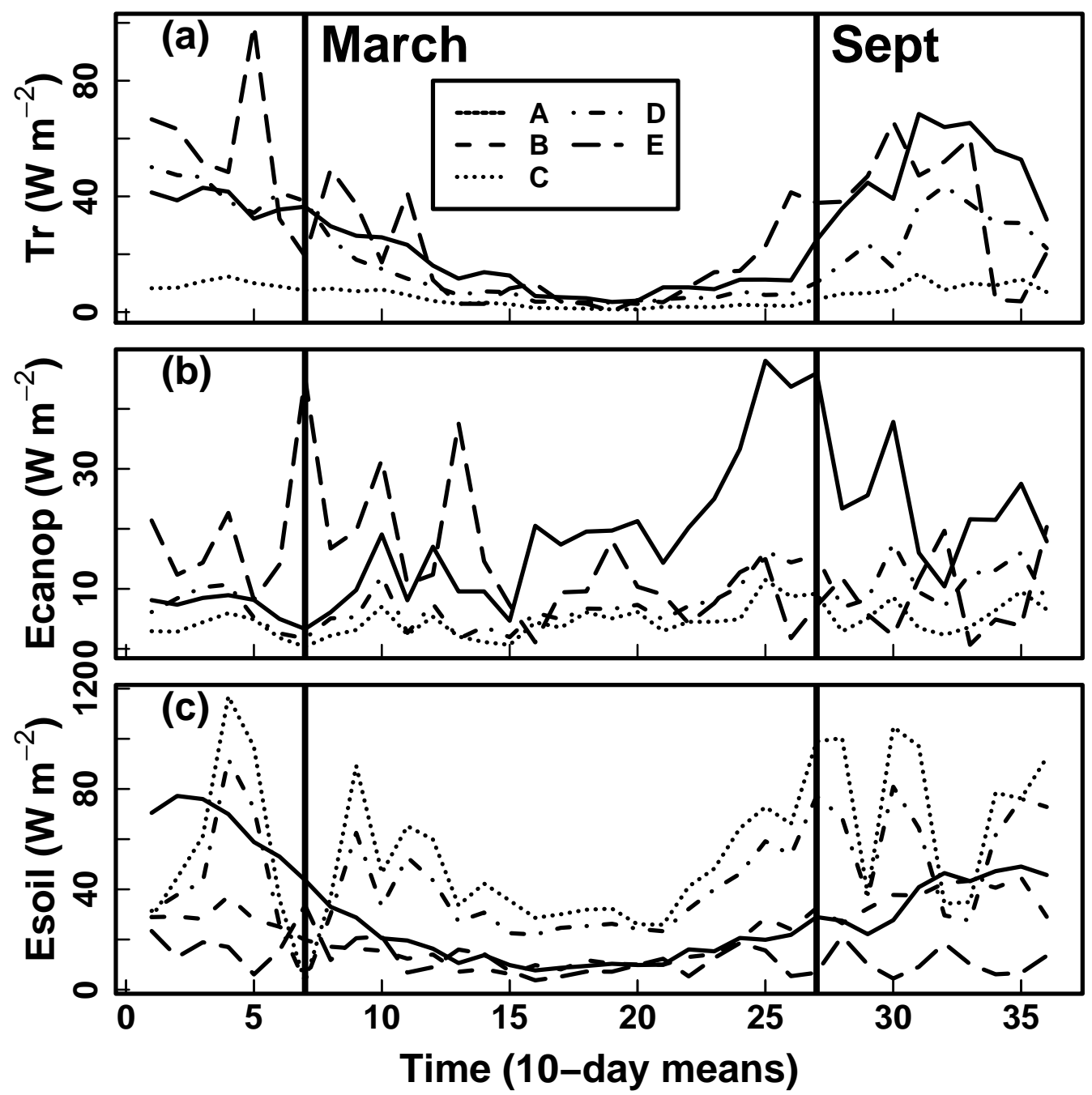

Figure 19 